\title{
Water Supply and Regulation of Underground Reservoir in Coal Mine considering Coal-Water Occurrence Relationship
}

\author{
Mingbo Chi $\mathbb{D}^{1},{ }^{1,2}$ Zhiguo Cao $\mathbb{D}^{1,2}$ Quansheng Li, ${ }^{1}$ Yong Zhang, ${ }^{1,2}$ Baoyang Wu $\mathbb{D}^{1,},{ }^{1,2}$ \\ Bao Zhang, ${ }^{1,2}$ Yi Yang, ${ }^{1,2}$ and Xiaoqing Liu ${ }^{1,3}$ \\ ${ }^{1}$ State Key Laboratory of Water Resource Protection and Utilization in Coal Mining, Beijing 100011, China \\ ${ }^{2}$ National Institute of Clean-and-Low-Carbon Energy, Beijing 102209, China \\ ${ }^{3}$ Shenhua Shendong Technology Research Institute, Shaanxi 719315, China
}

Correspondence should be addressed to Mingbo Chi; mingbo.chi@chnenergy.com.cn and Zhiguo Cao; zhiguo.cao@chnenergy.com.cn

Received 22 November 2021; Accepted 27 December 2021; Published 22 January 2022

Academic Editor: Afshin Davarpanah

Copyright (c) 2022 Mingbo Chi et al. This is an open access article distributed under the Creative Commons Attribution License, which permits unrestricted use, distribution, and reproduction in any medium, provided the original work is properly cited.

Water supply prediction and control is one of the key issues in exploitation of coal mine underground reservoirs (CMUR). In order to investigate the water supply for underground reservoirs in coal mines, the aquifers were classified into three types (types I, II, and III) according to the relative location of aquifers. The discrete element fluid structure coupling numerical simulation model is constructed according to the classification results. The numerical simulation parameters are inversed based on the surface subsidence data and the advance support pressure, and then, the disturbed characteristics and water pressure variation law of different types of aquifers are studied. The research results show that the maximum water inflow of type III, type II, and type I aquifers is $739 \mathrm{~m}^{3} / \mathrm{h}, 377 \mathrm{~m}^{3} / \mathrm{h}$, and $279 \mathrm{~m}^{3} / \mathrm{h}$, respectively. The dynamic calculation process of underground reservoir capacity under mining disturbance is refined, and the regulation and storage methods of underground reservoir are preliminarily put forward.

\section{Introduction}

With the implementation of China energy strategy, the western mining area has become the "main battlefield" for the development and utilization of coal resources. The output and reserves of coal in the five western provinces (Shanxi, Shaanxi, Mongolia, Ningxia, and Xinjiang) account for more than $70 \%$ of the national total, while their water resources account for only $3.9 \%$ of the total. Under the background characterized by "rich coal, poor water, and weak ecology," water resources have become a "bottleneck" restricting the development of coal industry in China western areas. The "ecological loss" derived from traditional extensive mining far exceeds the "economic value" created by coal development. The ecological environment problem, especially the water resources protection in western mining areas, has become the major problem faced by the coal industry [1-4]. According to statistics, China's annual output of mine water is about 8 billion tons, of which 6 billion tons are wasted, which accounts for about $60 \%$ of the industrial and civilian water. If the mine water can be fully utilized, there will be abundant water for downstream coal processing [1, 5-7]. Therefore, "protection and utilization of mine water" has become a strategic requirement for sustainable development as well as an important prerequisite for the green development of coal resources.

At present, many scholars have carried out extensive theoretical researches and engineering practices on "waterpreserved mining." From the perspective of "blocking, interception and drainage," a lot of researches have been conducted on mining-induced fissures and rock movement in order to master the development law of mining-induced fissures and investigate the impact of coal mining on water resources. Through theoretical analyses, experimental researches, and engineering practices, researchers have put forward theoretical and engineering technical means such 

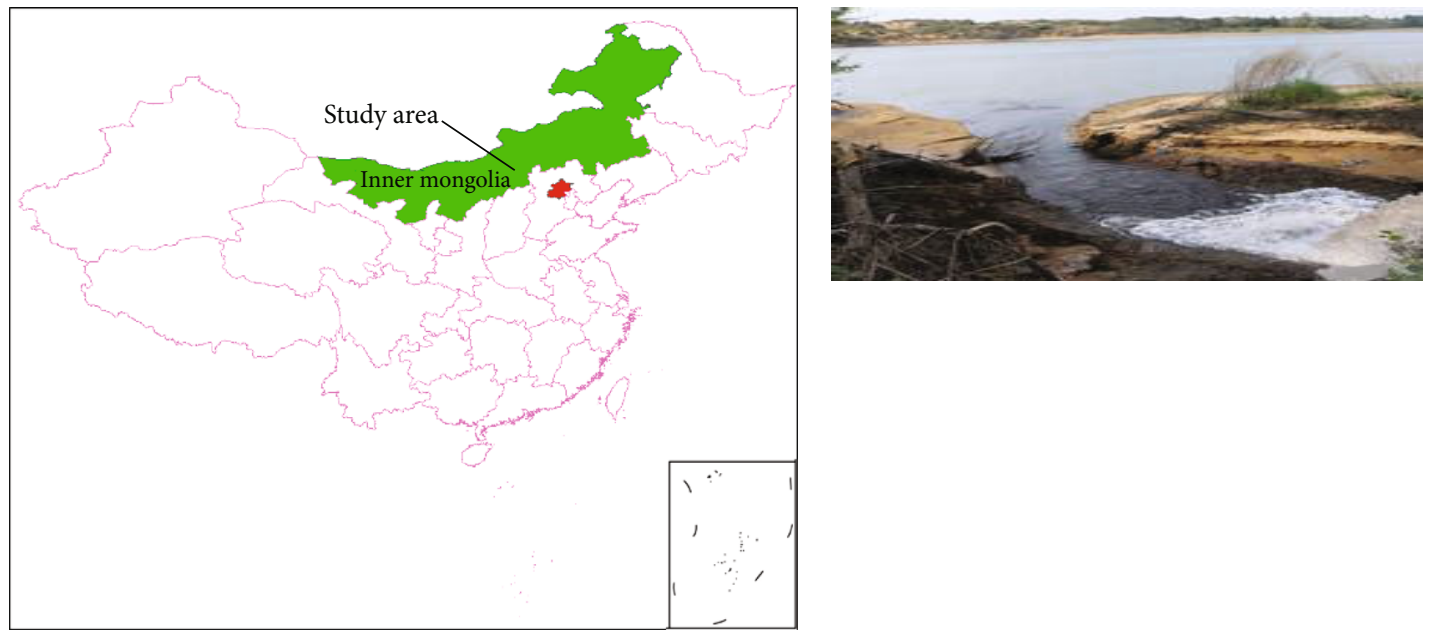

(a) Location map of the study area

(b) Supplement a map with water

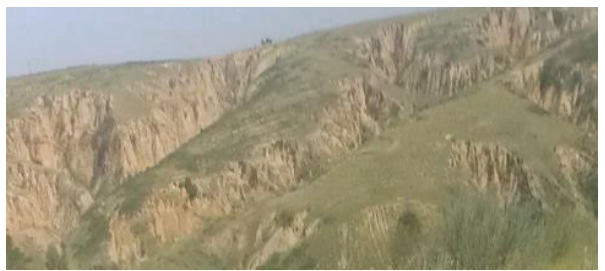

(c) Scarce vegetation

Figure 1: Overview of study area.

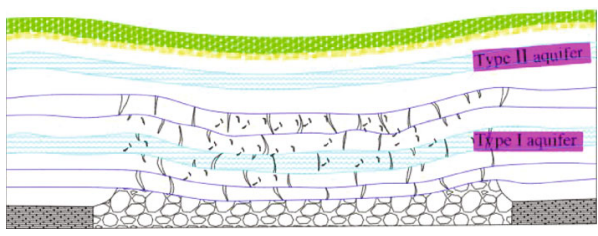

(a) Lower limit aquifer (type I aquifer)

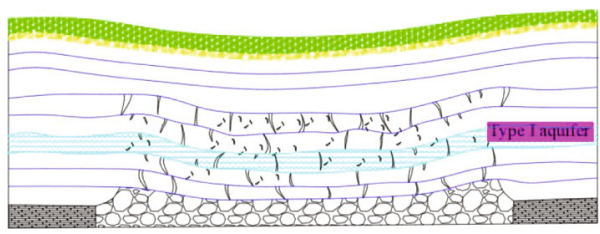

(b) Upper limit aquifer (type II aquifer)

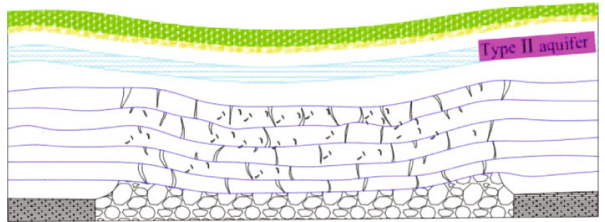

(c) Mixed aquifer (type III aquifer)

FIGURE 2: Generalized classification of coal-water occurrence relationship in shallow coal seam.

as height-limiting mining, mining with filling, and ground water storage in order to avoid or reduce the degree of damage to water resources caused by mining and thereby solve the contradiction between coal mining and ecological environment [8-11]. However, these mining protection methods and technologies have certain limitations. For example, height-limiting mining reduces the coal recovery rate and causes the waste of resources; ground water storage is limited due to the problems such as insufficient water storage space and high costs of water storage. In addition, there are still theoretical and technical difficulties in the study on the relationship between the development of mininginduced fissures and the destruction of aquifers, which are also key issues to be addressed in the protective exploitation of water resources.

After more than 20 years of scientific and technological researches and engineering practices, Gu Dazhao first proposed the concept of "diversion, storage and use" for underground reservoirs in coal mine. At present, more than 30 underground reservoirs have been successfully constructed in the Shendong mining area, with an annual water storage capacity of about 32 million $\mathrm{m}^{3}$, which contributes a lot to the ecological development, industrial production, and domestic water use in the mining area [1]. After years of researches and explorations, the academic community has carried out a large number of theoretical and engineering 


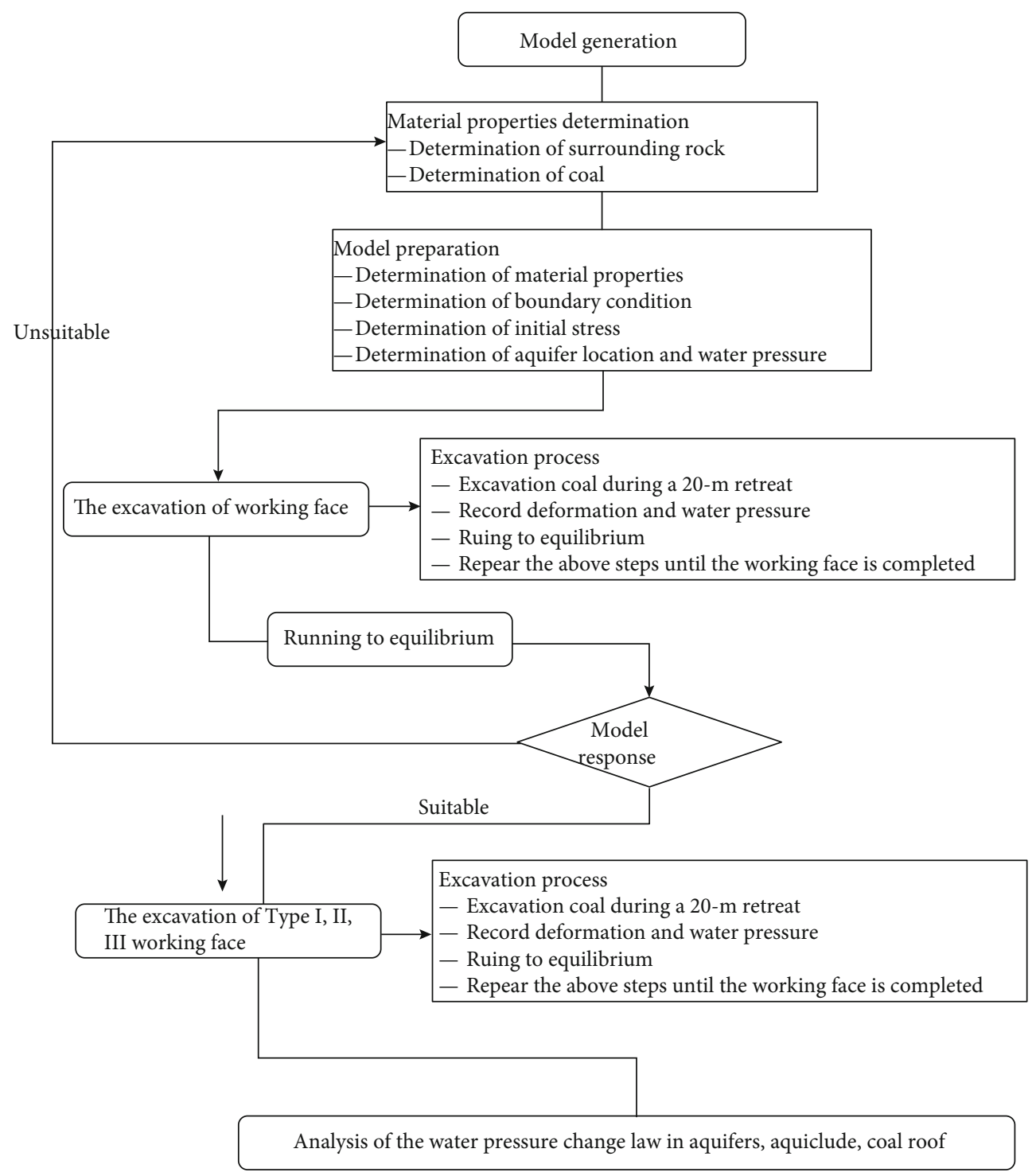

FIGURE 3: Flow chart of numerical simulation.

TABle 1: Physical and mechanical parameters of rock stratum.

\begin{tabular}{|c|c|c|c|c|c|c|c|}
\hline $\begin{array}{l}\text { Types of } \\
\text { rocks }\end{array}$ & $\begin{array}{c}\text { Bulk density } \\
\mathrm{kN} / \mathrm{m}^{3}\end{array}$ & $\begin{array}{c}\text { Compressive strength } \\
\sigma_{t} / \mathrm{MPa}\end{array}$ & $\begin{array}{c}\text { Internal friction } \\
\text { angle }\end{array}$ & Cohesion & $\begin{array}{c}\text { Elastic modulus } \\
E / \mathrm{GPa} \\
\end{array}$ & $\begin{array}{l}\text { Poisson's } \\
\text { ratio } \mu\end{array}$ & $\begin{array}{c}\text { Permeability } \\
\text { coefficientc } \mathrm{m} / \mathrm{s}\end{array}$ \\
\hline Aeolian sand & 15.8 & - & 20 & 0.02 & - & - & $1 \times 10^{-9}$ \\
\hline Conglomerate & 23.9 & 45.3 & 39 & 7.10 & 33 & 0.25 & $3 \times 10^{-4}$ \\
\hline $\begin{array}{l}\text { Sandy } \\
\text { mudstone }\end{array}$ & 22.4 & 22.8 & 38 & 6.32 & 23 & 0.28 & $1 \times 10^{-11}$ \\
\hline Siltstone & 23.5 & 40.6 & 38 & 7.07 & 35 & 0.25 & $2 \times 10^{-7}$ \\
\hline Coal & 15.1 & 6.60 & 30 & 2.00 & 14 & 0.22 & $1 \times 10^{-6}$ \\
\hline Mudstone & 22.3 & 20.7 & 29 & 5.55 & 20 & 0.30 & $3 \times 10^{-10}$ \\
\hline $\begin{array}{l}\text { Fine } \\
\text { sandstone }\end{array}$ & 23.4 & 6.60 & 38 & 6.46 & 13 & 0.22 & $1 \times 10^{-8}$ \\
\hline
\end{tabular}

practices on site selection for underground reservoir, body design of reservoir dam, and reservoir design. Key technologies such as water source prediction, reservoir site selection, and storage capacity design have been put forward to guarantee the safety of reservoir operation. It is worth noting that water source prediction is the basic prerequisite for the 


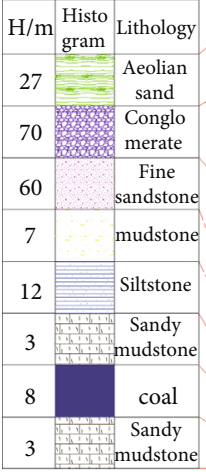

(a) Composite borehole histogram

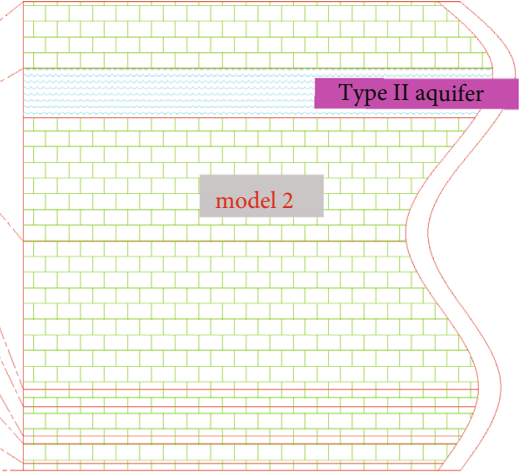

(b) Type I

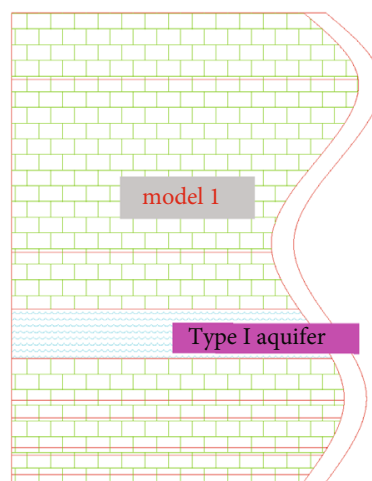

(c) Type II

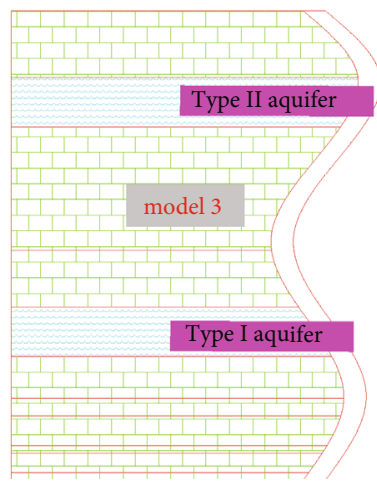

(d) Type III

FIGURE 4: Generalization model for numerical simulation.

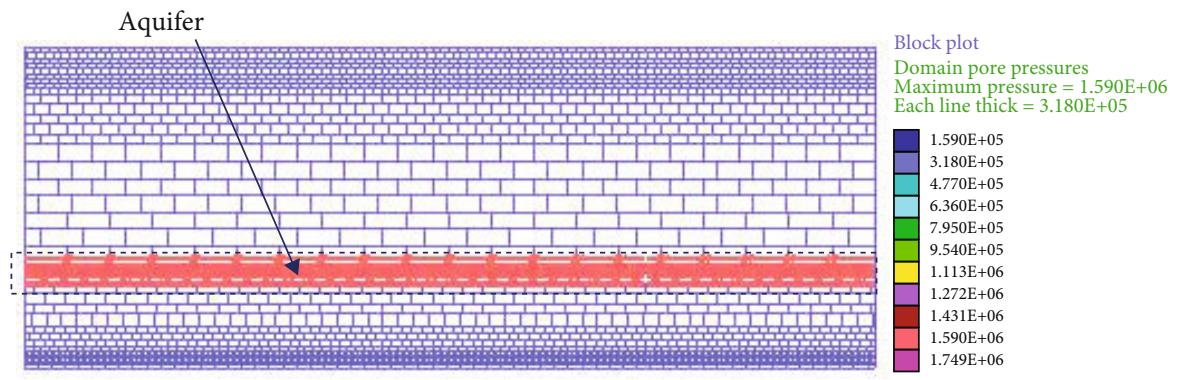

(a) Type I aquifer

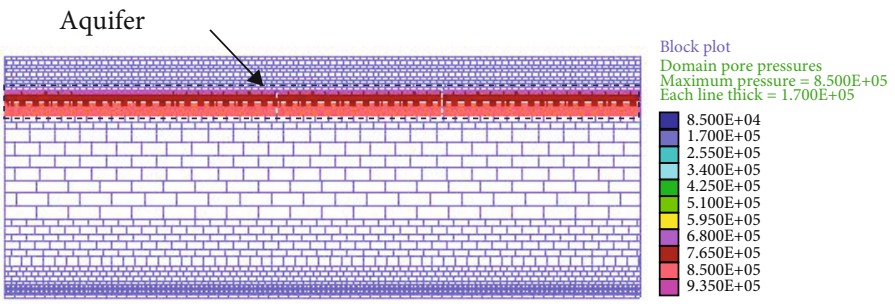

(b) Type II aquifer

Aquifer

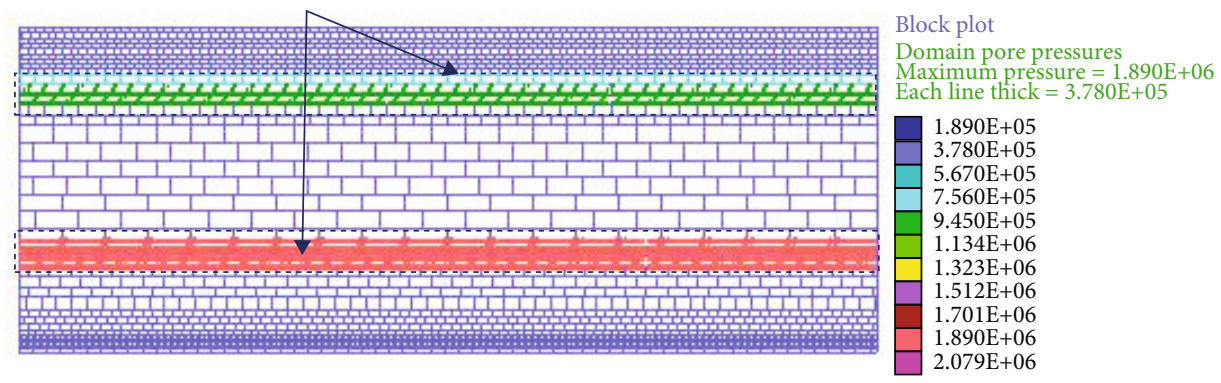

(c) Type III aquifer

Figure 5: Numerical modeling.

construction of underground reservoirs in coal mine, which includes two aspects: groundwater migration law research and groundwater volume prediction. Mine water inflow is the basis of a series of water storage activities in goaf such as underground reservoir capacity design, safe operation of underground reservoir, and mine water supply [12-17]. At present, water source prediction is mainly based on the actual monitoring data of mine water inflow. In fact, most of the water sources of underground reservoirs derive from the overlying aquifer of the coal seam, which is closely related to the law of disturbance of the aquifer. Therefore, determining the change law of aquifer under the influence 


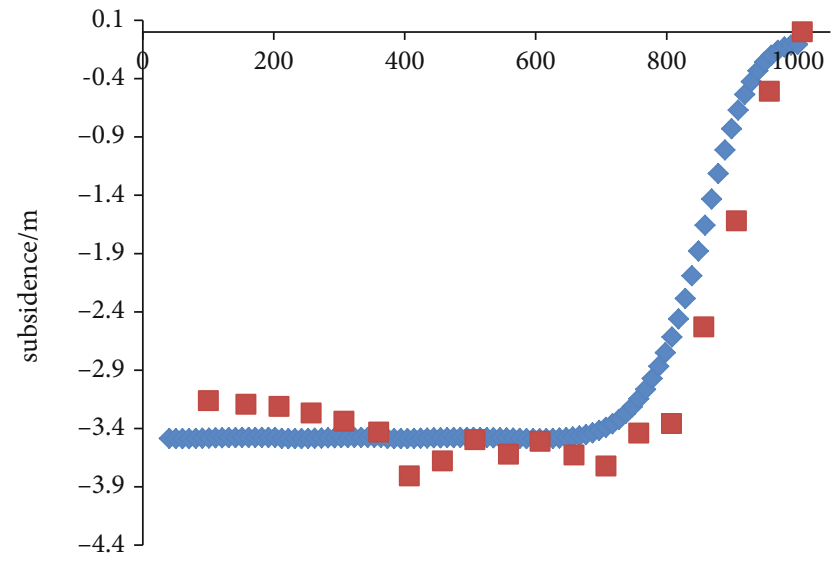

advance distance of working face/m

- Numerical simulation

- On-site measurement

Figure 6: Comparison of surface subsidence data and simulation results.

of mining is the basis for the study of reservoir water sources. In addition, coal seams in the western mining areas are typically characterized with shallow burial depth, big thickness, variable aquifer locations, and uncertain aquifer layers $[18,19]$, which brings big problems in the prediction of underground reservoir water sources.

Taking the Bulianta coal mine in Shendong mining area as example, this study presents fluid-solid coupling numerical analysis by using UDEC discrete element simulation software, studies the aquifer change law under the impact of mining, comparatively studies the water pressure changes of aquifers in different models, analyzes the water source of the underground reservoir, and proposes the water source control method for underground reservoir. The research results carry academic significance for accurately predicting the water source of underground reservoirs in coal mines.

\section{Generalized Classification of "Coal-Water" Occurrence Relationship in Shallow Coal Seams}

\subsection{Analysis of Main Factors Influencing Aquifer Changes} under Mining Action. After the coal seam is mined, the original balance state of the rock layer is destroyed, which leads to the deformation of the overlying rock mass and the generation of mining-induced fissures, resulting in the change of permeability of the overlying coal seam (Figure 1). On this basis, the mining-induced fissures continue to expand under the "mining stress-water" coupling effect, which eventually become a channel for water loss, causing water resources to flow to the goaf. In fact, there are two necessary conditions for water resources derived from aquifers to enter the goaf: one is that the mining-induced fissures communicate with the aquifer, and the other is that the fissures develop into water-conducting fissures. When either of the two con- ditions is not satisfied, loss of water resources in the aquifer will not be resulted. For example, when the overlying rock is soft rock or contains kaolin, illite, and other water-swelling minerals, the water-conducting fissures will gradually close after a certain period of time; the water level of the aquifer will gradually recover, so that the loss of water resources will gradually decrease. Therefore, water-conducting fissure zone is one of the main factors causing the change of aquifers. In the research process, it is necessary to consider the development height of the fissures and also analyze whether the fractures can develop into water-conducting channels. Only when the fissures communicate with the aquifer and develop into water-conducting channels, it will impose threat to the aquifer, which is very important for water supply during the construction of underground reservoirs in coal mines.

Regarding the problem of mining-induced fissures, many scholars have conducted a lot of researches by theoretical analysis and simulation deduction. It is believed that the main factors influencing mining-induced fractures are coal seam depth, mining thickness, mining speed, etc. The calculation formula and judgment standard of fissure development height have been put forward [11, 20-23]. Where roof lithology, burial depth, and lithological conditions can be regarded as internal factors affecting the development of water-conducting fissure zone, while mining height and working face size can be regarded as external factors. Factors such as mining thickness and mining speed affect the degree of roof rock destruction (fissure development), while roof lithology and combination means determine its ability to "resist" mining disturbances. According to the mininginduced damage on aquifer, impacts of mining-induced fissures on the aquifer can be classified into three cases. First, mining-induced fissures will not damage the stability of the aquifer; that is, it will not cause the loss of water resources in the aquifer. Second, mining-induced fissures destroy the aquifer stability, but after a period of time, the aquiclude gradually recovers its water-proof capacity, and the fissures lose the function of water conduction. Although there is a certain loss of water in the aquifer, the stability of the aquifer is not affected. Third, mining-induced fissures cause irreversible damage to the aquifer, and mining-induced fissures become seepage channels, so that a large amount of water resources flow to the goaf $[4,20]$. The main factor affecting the occurrences of the above three cases is the relationship between the development height of the water-conducting fissures and the occurrence location of the aquifer. Due to the shallow burial depth and great thickness of coal seams in western mining areas, fissures will develop to the surface after coal seams are mined. Therefore, its impact on aquifers basically accords with the second and third cases, causing a lot of waste of water resources. The construction purpose of underground reservoirs in coal mines is to introduce mine water into the goaf, so that it can be used after being sealed and fully purified. Therefore, it is necessary to generalize the classification of the occurrence modes of aquifers, link them with the development of mining-induced fissures, and then study its disturbance characteristics under different conditions to provide a basis for the prediction of water source in underground reservoirs. 


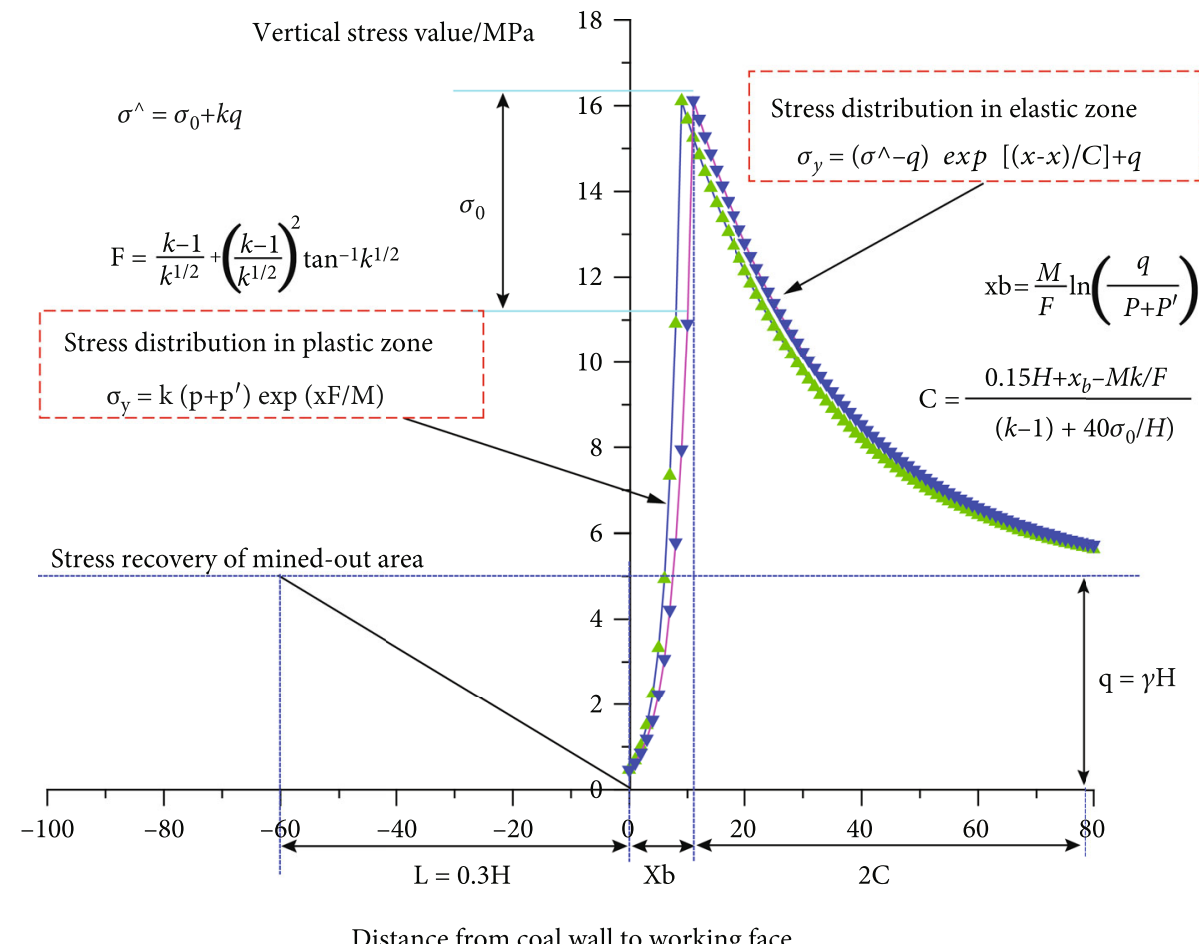

Distance from coal wall to working face

$\longrightarrow$ Numerical simulation

$\rightarrow$ Theoretical calculation

FIGURE 7: Distribution characteristics of abutment pressure in working face.

TABLE 2: Wilson's theoretical formula parameters.

\begin{tabular}{lcccccc}
\hline $\begin{array}{l}\text { Coal seam } \\
\text { thickness } / \mathrm{m}\end{array}$ & $\begin{array}{c}\text { Buried } \\
\text { depth/m } / \mathrm{m}\end{array}$ & $\begin{array}{c}\text { Triaxial } \\
\text { stress factor }\end{array}$ & $\begin{array}{c}\text { Lateral supporting pressure } \\
\text { at the coal wall/MPa }\end{array}$ & $\begin{array}{c}\text { Hydrostatic } \\
\text { pressure/MPa }\end{array}$ & $\begin{array}{c}\text { Uniaxial compressive } \\
\text { strength/MPa }\end{array}$ & $\begin{array}{c}\text { Uniaxial compressive } \\
\text { residual strength/MPa }\end{array}$ \\
\hline 5 & 200 & 2.3 & 0 & 5 & 5 & 0.2 \\
\hline
\end{tabular}

2.2. Generalized Classification of Coal-Water Relationship. Over the years, many scholars have carried out a large number of studies on the movement law of the overburden strata in shallow coal seams. It is concluded that the movement of the overburden strata in shallow coal seams has obvious "two belt" divisions in the vertical direction, and the disturbance characteristics of coal mining on aquifers are studied according to the development laws of the "two belts." In fact, the location of aquifer varies with the influence degree of mining. For underground reservoirs in coal mine, the aquifers at different locations provide varying degrees of recharge to the reservoir after mining disturbances. Considering this, this paper classifies the relationship between the aquifer location and the development height of the "two belts", and generalizes the aquifers into three types (as shown in Figure 2).

Type I aquifer: the lower aquifer, which is located between the caving zone and the fissure zone. When the aquifer is located at this position, the mining-induced fissures directly destroy the stability of the aquifer; the fissures communicate with the aquifer and become the main channel allowing the water source of the aquifer to flow to the goaf.

Type II aquifer: the upper aquifer, which is located above the fissure zone. This type of aquifer is less affected by fissure development than type I. Mining-induced fissures have not developed to the aquifer or have less impact on the stability of the aquifer. Water resources in the aquifer will flow downwards only when fissure penetrates the aquifer and forms a water-conducting channel.

Type III aquifer: mixed type aquifer, which coexists with type I aquifer and type II aquifer. Generally, this type of aquifer is dominant in the process of coal seam excavation. Different mining methods and geological conditions have greatly different effects on the aquifers, and the water supply to underground reservoirs in coal mine is also different.

Type I and type II aquifers are collectively referred to as single type aquifer. It can be determined that the water source of the underground reservoir basically comes from this type of aquifer. Type III aquifer is a combination of the other two types of aquifers. In the case of Type III aquifer, the water source of the underground reservoir is supplied by two or more aquifers. Since type I aquifer is in the fissure zone, the destruction degree is larger compared to type II. Therefore, type I aquifer may become the main water source for underground reservoirs. In order to clarify the recharge of aquifers to the underground reservoirs under different conditions, it is necessary to analyze the failure 


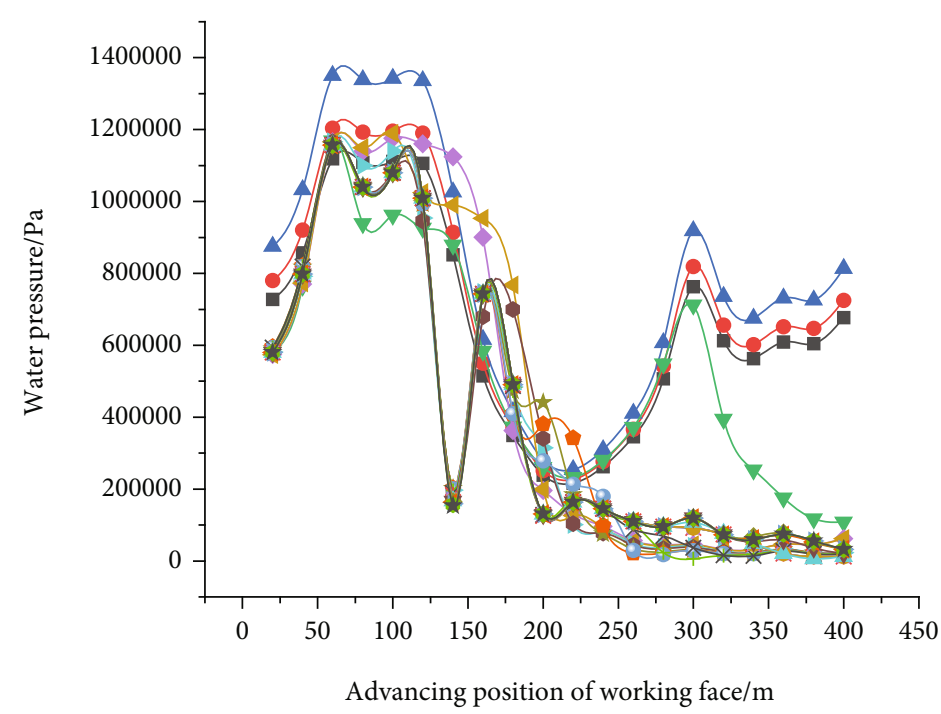

(a) Lower aquifer of model 1

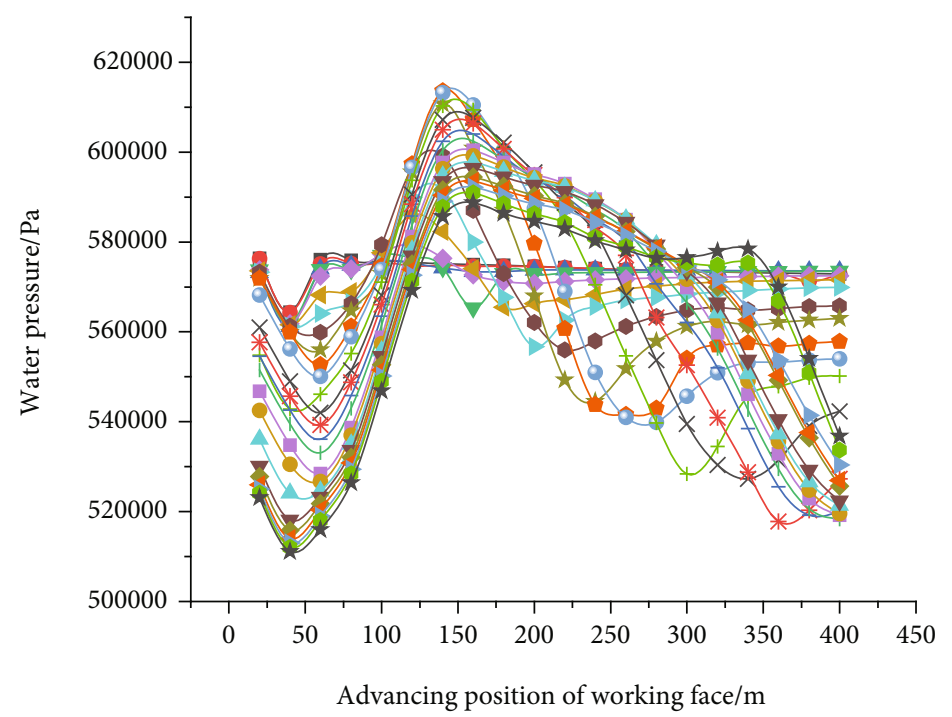

(b) Lower aquifer of model 2

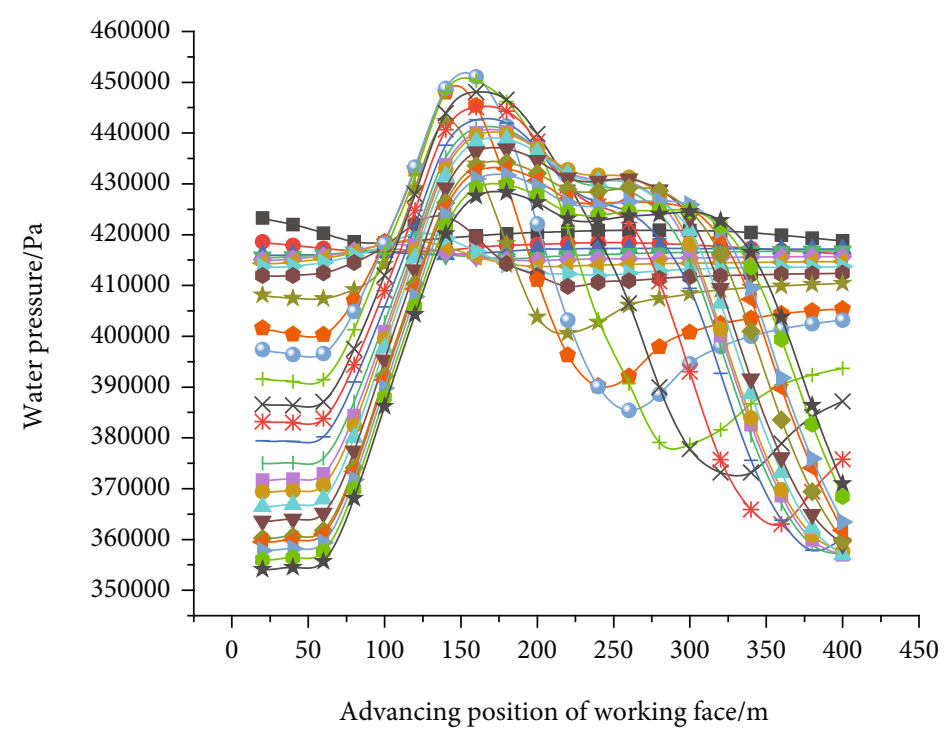

(c) Model 3 (type II aquifer)

Figure 8: Continued. 


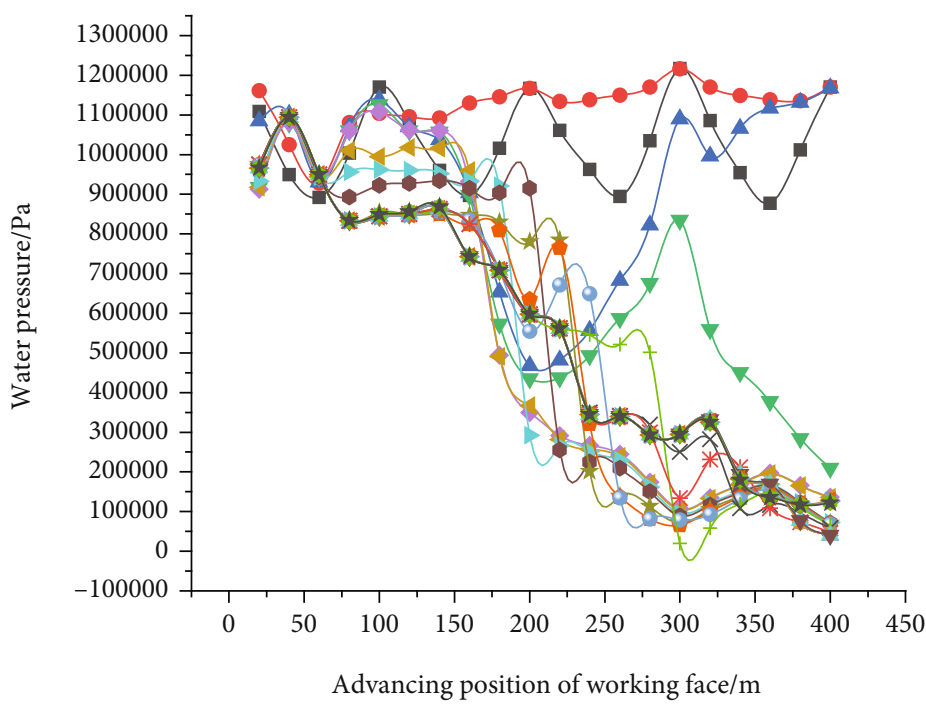

(d) Model 3 (upper part of type I aquifer)

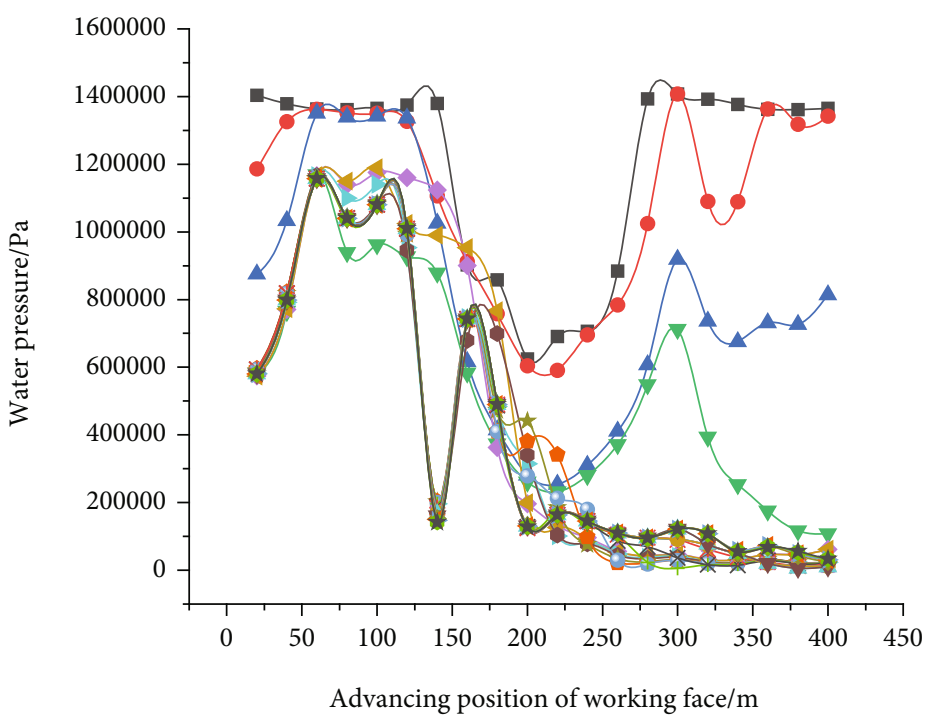

\begin{tabular}{|c|c|}
\hline-0 & $* 160$ \\
\hline-10 & -180 \\
\hline-20 & +200 \\
\hline$-\nabla 30$ & $-[-220$ \\
\hline$\neg 40$ & -240 \\
\hline-450 & -260 \\
\hline$\rightarrow-60$ & $-\nabla 280$ \\
\hline-70 & $->300$ \\
\hline$\star 80$ & -320 \\
\hline-90 & $\rightarrow-340$ \\
\hline-100 & -360 \\
\hline+120 & $\star-380$ \\
\hline$\succ 140$ & \\
\hline
\end{tabular}

(e) Model 3 (lower part of type I aquifer)

FIGURE 8: Variation law of water pressure in aquifer. 


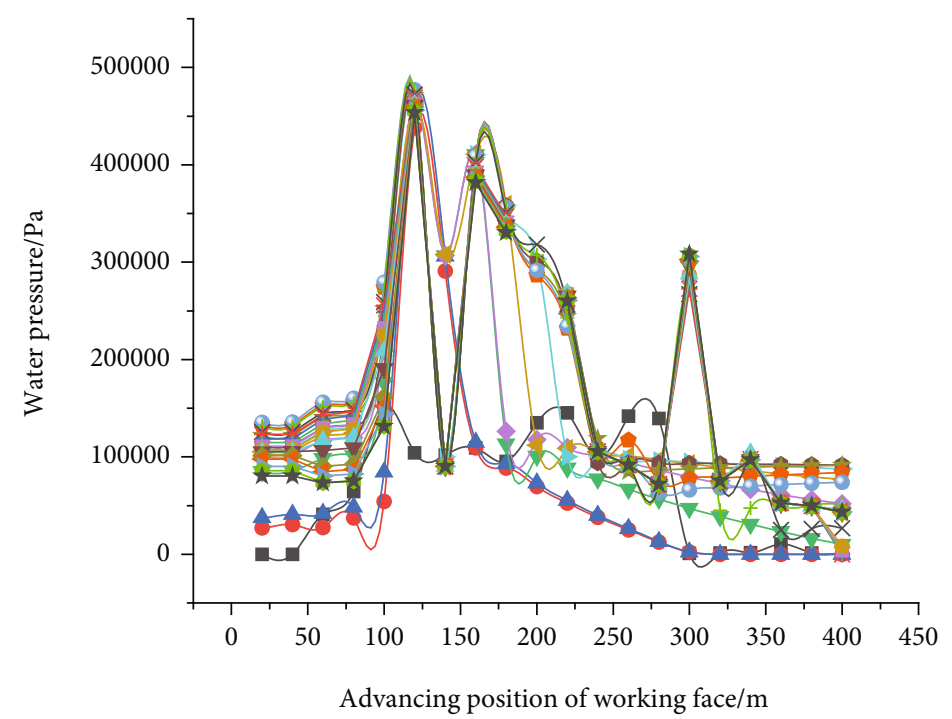

(a) The upper part of coal seam in model 1

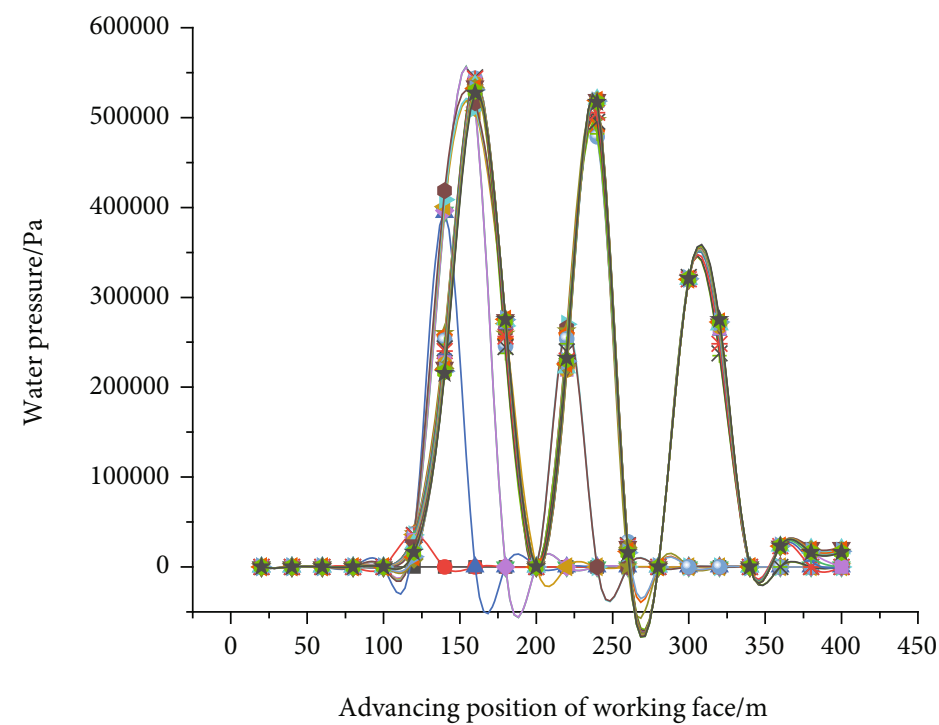

(b) The upper part of coal seam in model 1

Figure 9: Continued. 


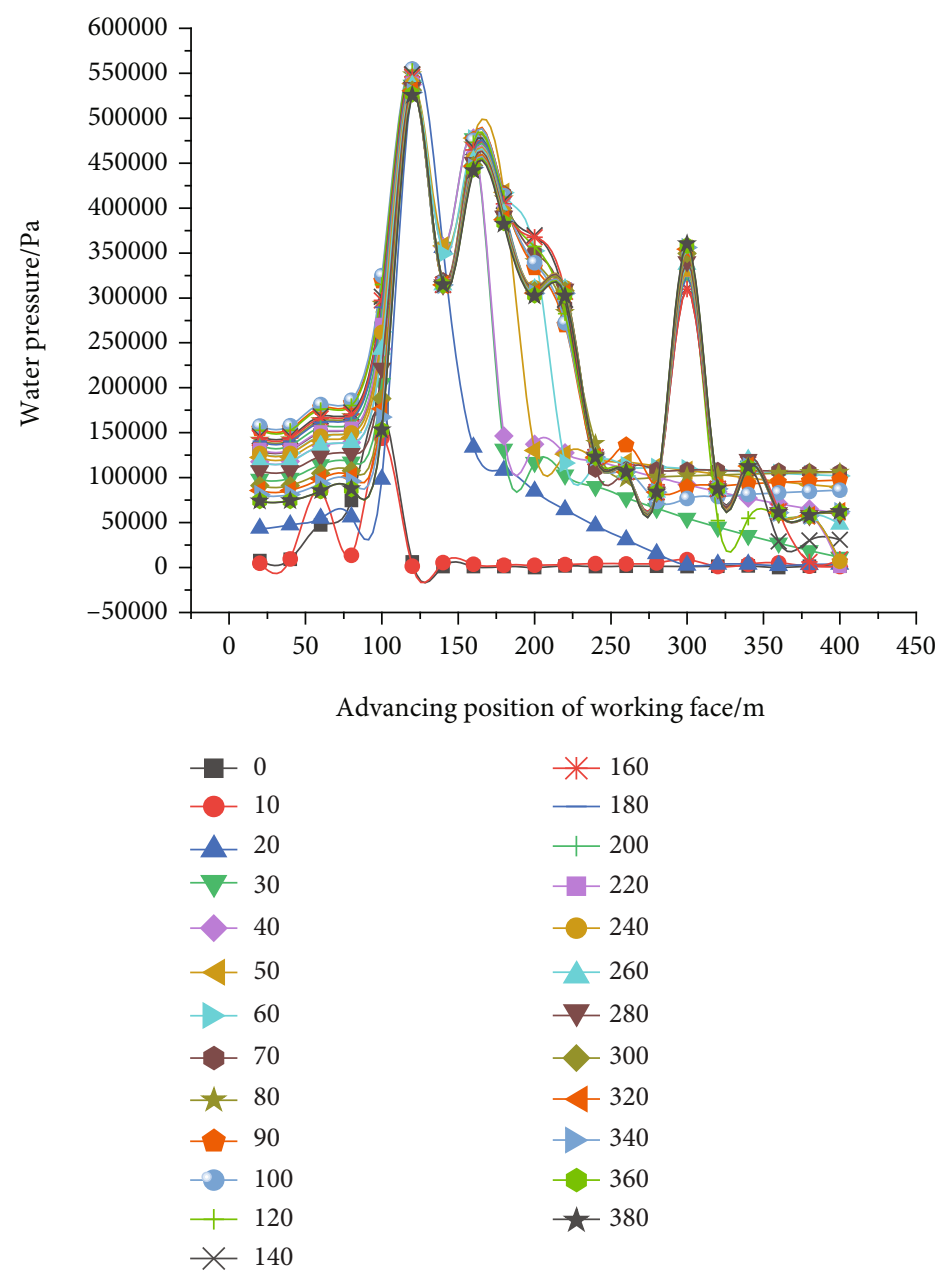

(c) The upper part of coal seam in model 1

FIGURE 9: Variation law of water pressure at coal roof.

characteristics of various types of aquifers under the influence of mining.

\section{Numerical Model and Result Analysis}

The Discrete Element Method (DEM) believes that the rock mass is composed of rock blocks and discontinuous surfaces between the blocks. DEM can be used to describe the geometric characteristics (fracture length, inclination, opening degree, spacing, etc.) of rock mass cracks more truthfully. Therefore, the DEM-based numerical calculation method has been widely used in the study of the hydraulic characteristics of rock (body) fissures.

In the simulation process, the mechanical deformation of the joint will affect the hydraulic opening of the joint. The hydraulic opening of the joint is calculated by the following formula.

$$
\begin{gathered}
a=a 0+\triangle a, \\
\triangle a=\frac{\sigma n}{k n},
\end{gathered}
$$

where $a_{0}$ is the joint opening in the zero-stress state, $\sigma_{n}$ is the normal stress acting on the joint, $k_{n}$ is the stiffness of the joint, and $a_{\text {res }}$ is the residual hydraulic opening of the joint.

In the process of stress change, the crack opening changes, the flow rate of each node changes, and the pore pressure of the original domain also changes. The pore pressure of the new area can be calculated by following formula:

$$
P=P_{0}+K_{w} Q \frac{\triangle t}{V}-K_{w} Q \frac{\triangle V}{V},
$$

where $P$ is the updated regional pressure, $\mathrm{Pa} ; P_{0}$ is the original regional pressure, $\mathrm{Pa} ; K_{w}$ is the bulk modulus of the fluid, $\mathrm{MPa}$; $Q$ is the total flow rate of the regional interconnection joints, $\mathrm{m}^{2} / \mathrm{s} ; \Delta V=V-V_{0}, V_{m}=\left(V+V_{0}\right) / 2, V$, and $V_{0}$ are the areas of the new and old regions, respectively; and $\Delta t$ is the time step.

3.1. Establishment of Numerical Model Based on Generalized Classification. Bulianta Coal Mine is located in the central part of Shendong Mining Area. The main coal seam is No. $1^{-2}$, with the average thickness of the coal seam of $7.44 \mathrm{~m}$, so one-time full-thickness mining technology is adopted. 


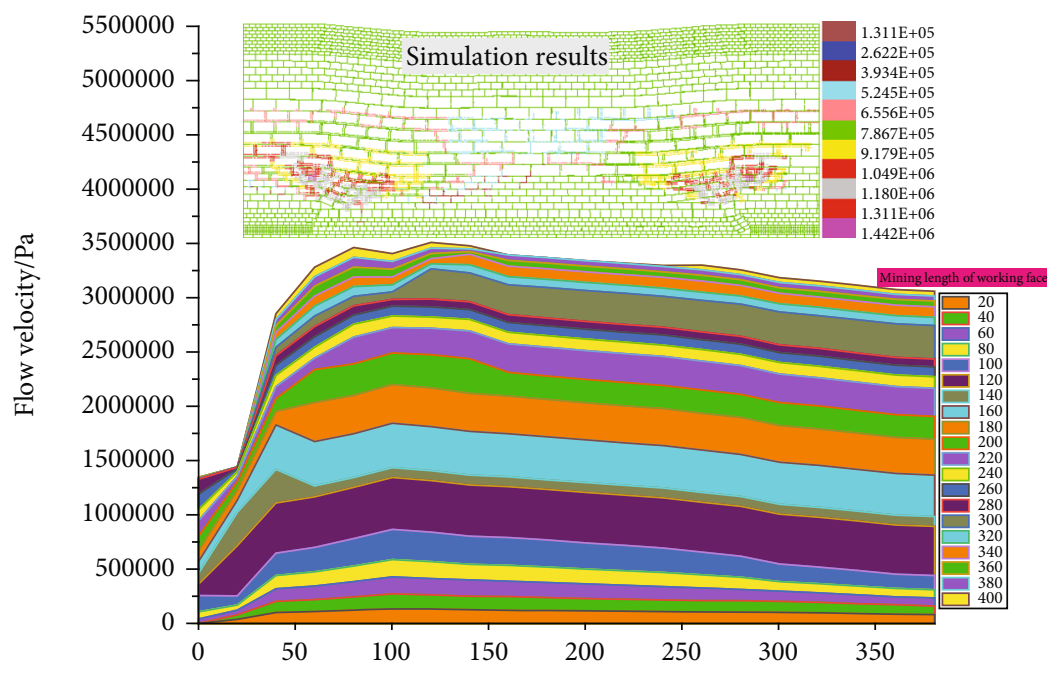

Advancing distance of working face $/ \mathrm{m}$

(a) Model 1

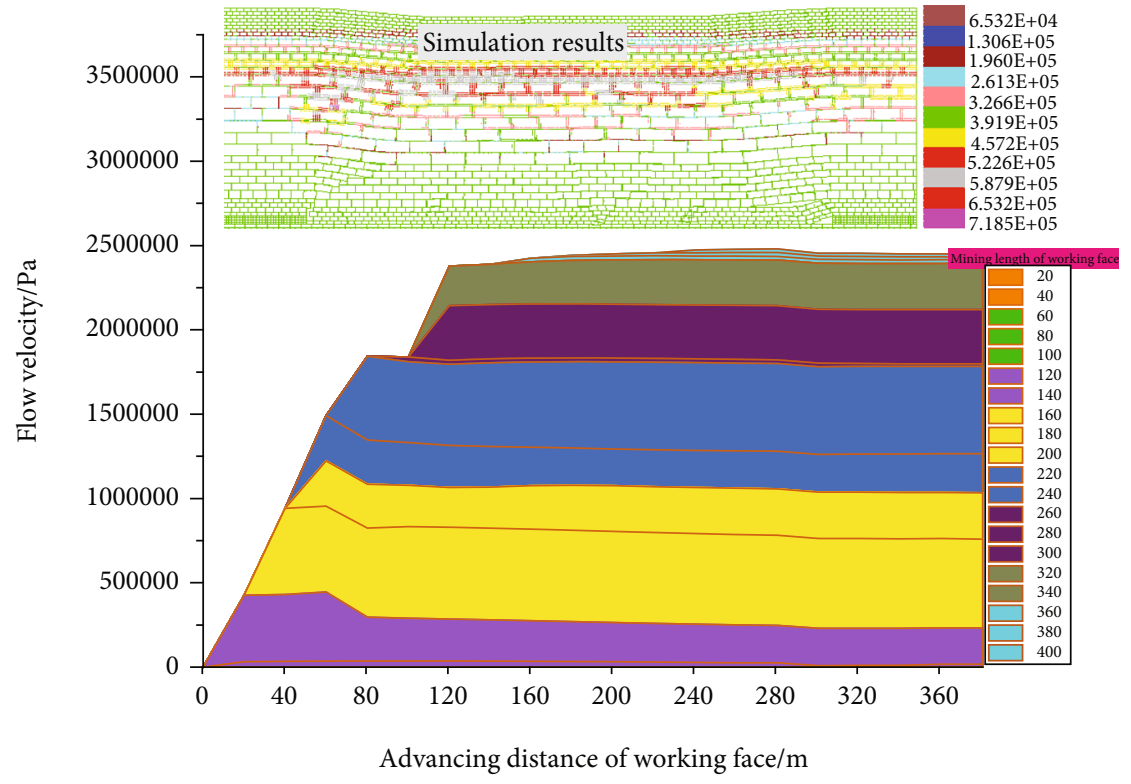

(b) Model 2

Figure 10: Continued. 


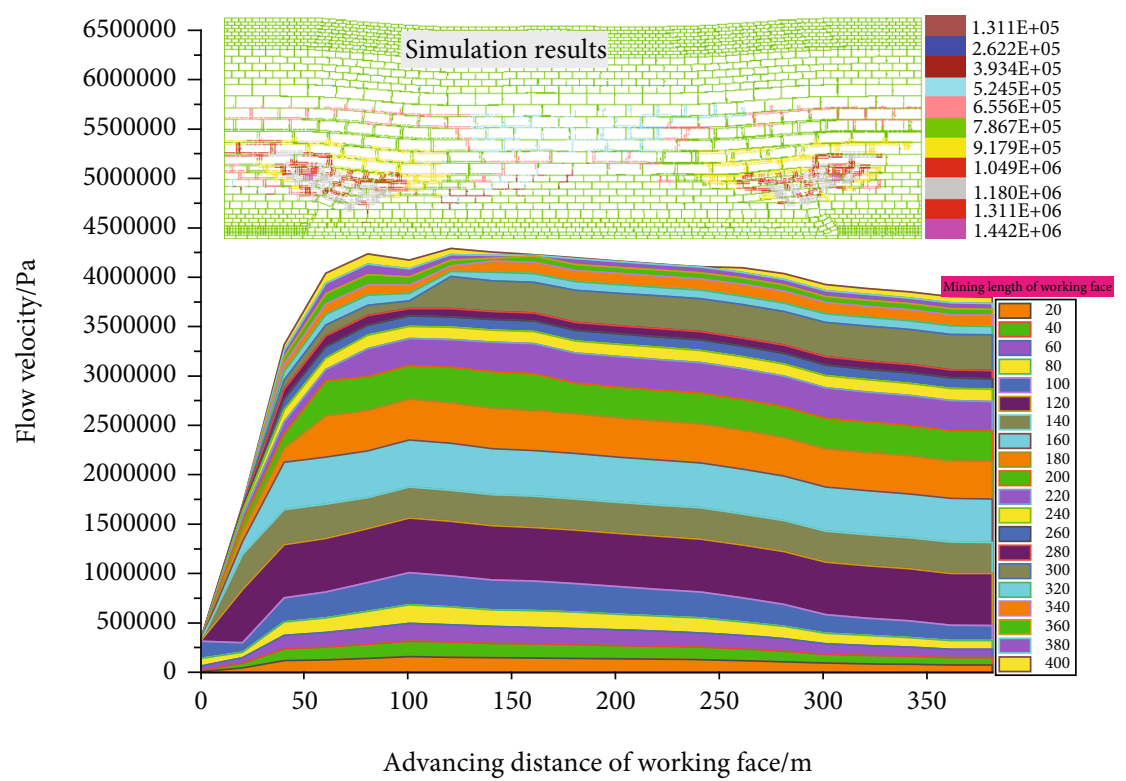

(c) Model 3

FIGURE 10: Variation law of water pressure at coal roof with the advancement of working face.

There are mainly two aquifers in the upper part of the coal seam, namely the Quaternary aquifer and the Zhidan Group aquifer of the Lower Baixi System. The aquiclude is located on the top of the Yan'an Formation in the Lower Jurassic, and its lithology is mainly composed of mudstone and sandy mudstone. In order to analyze the water source problems during the construction of underground reservoirs after the mining of No. $1^{-2}$ coal seam, it is necessary to study the change law and recharge law of water source in the aquifer under the action of mining. In view of this, this paper uses the discrete and fluid model of the UDEC software (Figure 3) to conduct numerical simulation analysis based on the occurrence status of No. $1^{-2}$ coal seam and aquifer in Shendong Bulianta Coal Mine. A numerical analysis model is constructed to analyze the influence of coal mining on the aquifer as well as the influence of mine water occurrence modes on the water source of underground reservoirs. The physical and mechanical parameters of each rock layer of the model are shown in Table 1 [24, 25]. The size and basic parameters of each rock layer are selected as follows:

(1) Model size: according to the average burial depth of No. 1-2 coal seam, the model height is set to $190 \mathrm{~m}$; at the same time, considering the boundary effect and the full mining effect during the advancement of the working face, coal pillars with length of $60 \mathrm{~m}$ are arranged on the left and right sides, and the model length is set to $500 \mathrm{~m}$; excavation step distance is set to $10 \mathrm{~m} / \mathrm{step}$. (2) Selection of mining height: based on the actual mining thickness of No. 1-2 coal seam, the mining height is set to $8 \mathrm{~m}$. (3) Aquifer: according to the above generalized model, a total of 3 sets of models are set up based on the aquifer location. Model 1 and model 2 are given a set of aquifers, namely, type I and type II aquifers, model 3 has two aquifers, and the aquifer thickness for the three types of models is set to $20 \mathrm{~m}$, as shown in Figure 4. The modeling results are shown in Figure 5; (4) monitoring line layout: during the simulation, the monitoring lines are arranged in the lower part of the aquifer (the upper and lower parts of the type I aquifer in model 3), the lower part of the aquiclude, and the upper part of the coal seam. The change characteristics of water pressure and water velocity during the excavation process are monitored, and the aquifer water level change law, seepage path, and other related information are inverted according to the change characteristics of water pressure.

The leading-support stress distribution of working face is obtained based on numerical calculation model, and ground surface displacement subsidence curve is plotted based on Wilson's theoretical calculations and field measured data (Figures 6 and 7). The error rate of the ground settlement monitoring data is $7.95 \%$, and the error rate of the leading-support peak stress is $1.86 \%$. The deviation between the numerical simulation model and the actual measurement and theoretical calculations are within $10 \%$, showing good consistency. The calculation method of the specific values refers to the calculation method using the Wilson theory [26-28] formula. The parameters required in the theoretical formula when the mining height is $5 \mathrm{~m}$ are summarized in Table 2 .

\subsection{Disturbance Characteristics of Aquifer under Mining.} According to the characteristics of water pressure change at the measuring point, the characteristics of the aquifer change under the mining action can be obtained. Through studying the dynamic changes of the water pressure before and after mining, we can obtain the change characteristics of the water resources under the mining action, understand the water pressure change laws of aquifers, aquiclude, and coal roofs, respectively, and then grasp the disturbance characteristics of different types of aquifers under mining. 


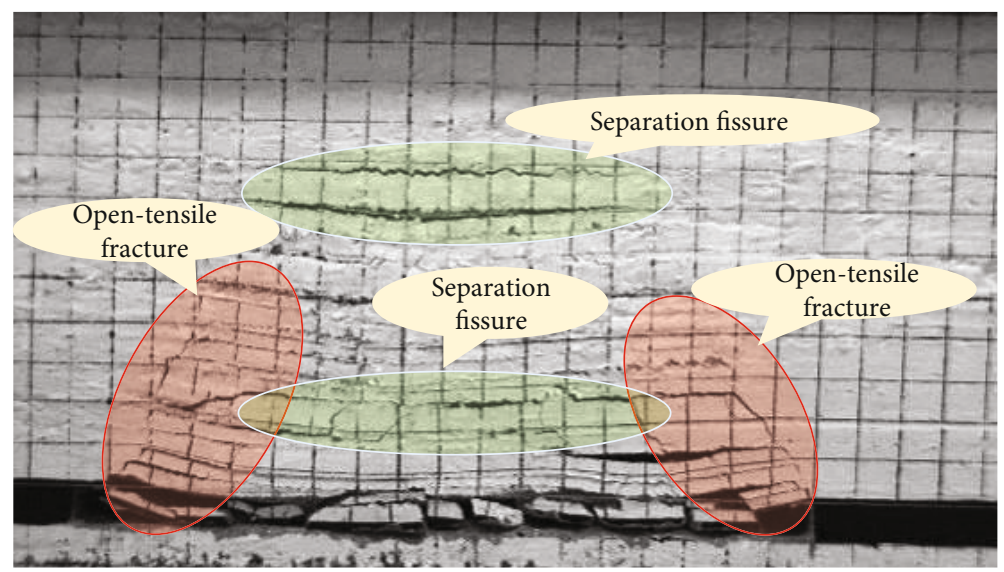

(a) The development characteristics of fissures when mining to the middle

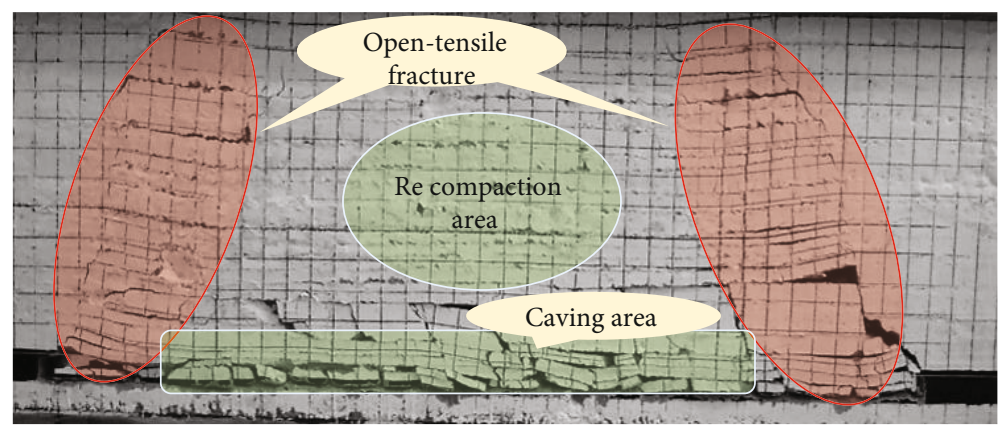

(b) The development characteristics of fissures after mining in the working face

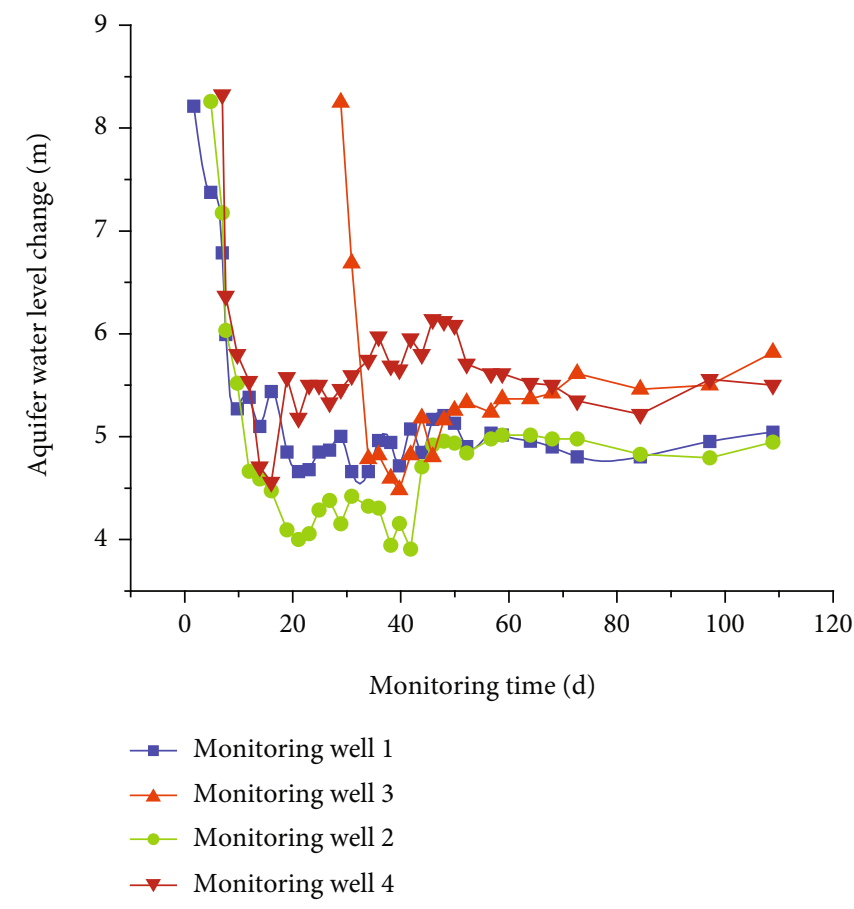

(c) Monitoring results of aquifer water level

FIGURE 11: Comparison and verification of simulation and on-site monitoring results.

3.2.1. Analysis of the Change Law of Water Pressure in Aquifers. The direct reason why coal mining has an impact on the aquifer is that the fissures become water-conducting channels, and the mining-induced fissures continue to open and close during the advancement of the working face. In this process, the mining-induced fissures will increase the water pressure in the overburden strata and reduce alternating changes. From the simulation results (Figure 8), it can be 


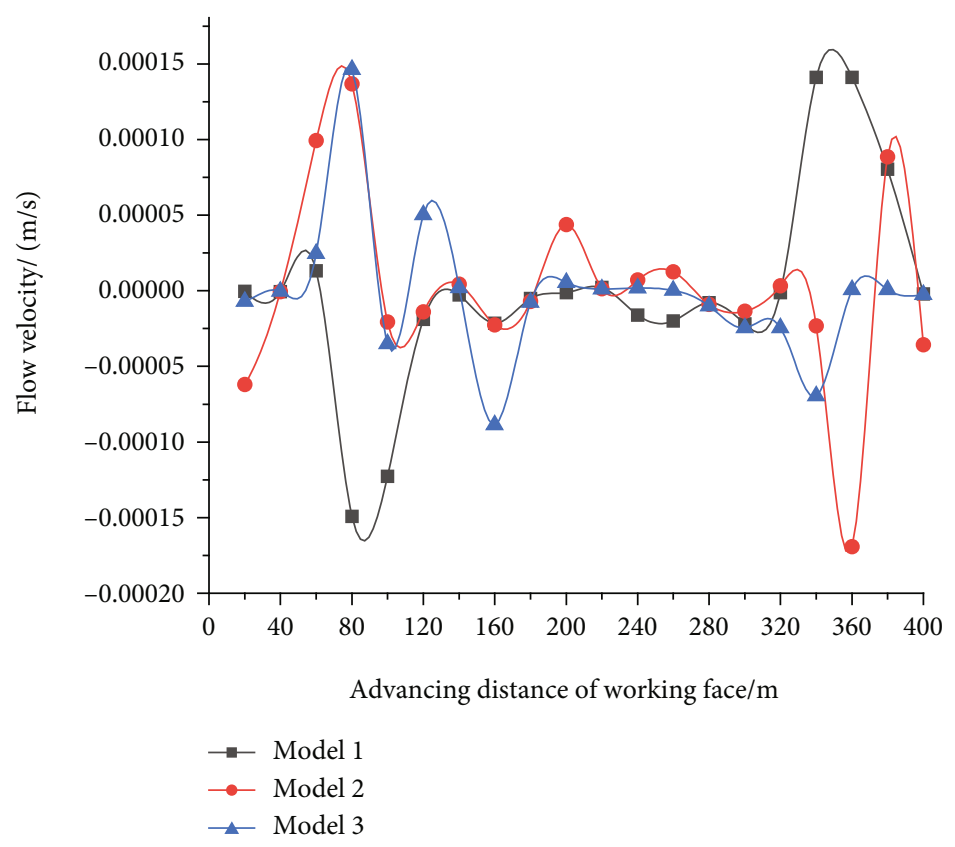

FIGURE 12: Variation law of roof water velocity of each model.

seen that after the mining of the working face, the water pressure at different locations in aquifers shows the tendency of increasing or decreasing, and as the distance between the coal seam and the aquifer increases, the magnitude of the change tends to decrease. In the case of type III aquifer, the water pressure in the lower aquifer changes more significantly than that in the case of type II aquifer, and the upper water pressure in the lower aquifer also changes as the working face advances. When the working face advances to about $100 \mathrm{~m}$, the water pressure exhibits big fluctuations, indicating that the lower limit aquifer is "recharged" by the upper limit aquifer. In the case of type II aquifer (model 2), as the distance between the aquifer and the coal seam is greater than that in the case of type I aquifer, it is more affected by mining, and the water pressure at the same location changes earlier than that in the case of type I aquifer.

From the simulation results, it can be known that the aquifers at different locations present certain time effect. In general, there is a change characteristic of decrease $\rightarrow$ increa$\mathrm{se} \rightarrow$ decrease $\rightarrow$ recovery. The water resources located in the upper aquifer "migrate" along the mining-induced fissures to the lower rock layer or aquifer; when the aquifer is located in the upper part (type I), it is greatly affected by mining, and the disturbance time is later compared to type II aquifer; when the aquifer is type II or type III, the lower aquifer is greatly disturbed with serious water loss. In particular, when the aquifer is type III aquifer, the lower part of type II aquifer shows great water pressure changes, with more serious water loss, providing abundant water supply for underground reservoirs.

3.2.2. Analysis of the Change Law of Water Pressure in the Aquiclude. The change of water pressure in the aquiclude also reflects dynamic evolution of the fissures during coal seam mining as well as the strength of water resistance to a certain extent. According to the simulation results, the location of the aquifer greatly affects water pressure change in the aquiclude. As the distance between the two increases, the water pressure change in the aquiclude becomes smaller, and the time for the occurrence of water pressure change is slightly delayed. When the working face advances to about 180-200 m, the change law of water pressure basically tends to be stable, showing periodic fluctuations.

In the case of type III aquifer, the aquiclude has greater change amplitude and more significant increase of water pressure than the other two cases. In the case of type II aquifer, a stable "water gushing point" is formed about $100 \mathrm{~m}$ away from the open-off cut. It can be judged that the mining-induced fissure has the largest opening at this point, and the water source of the aquifer constantly flows to the goaf. Despite the great water resource flow at this point, the water pressure in the mining-induced fissure is small. In the case of type I aquifer, after the coal seam mining destroys the aquifer, water resources continue to flow to the lower rock layer and enter the goaf along the fissure of the aquiclude. In general, as the distance between the coal seam and the aquifer decreases, there is an increasingly serious loss of water resources in the aquifer, and the change law of water pressure becomes more and more complicated during the advancement of the working face. The farther away the occurrence location of aquifer is from the coal seam, the smaller the water pressure change is, and the longer the time will be. The difference in the water pressure change reflects the fissure opening degree or the strength of the water conductivity in the aquifer. The closer the distance between the aquifer and the coal seam, the more serious the loss of water resources after the mining-induced fissure destroys the aquifer, and the more stable the water supply to the underground reservoir. On the contrary, when the 


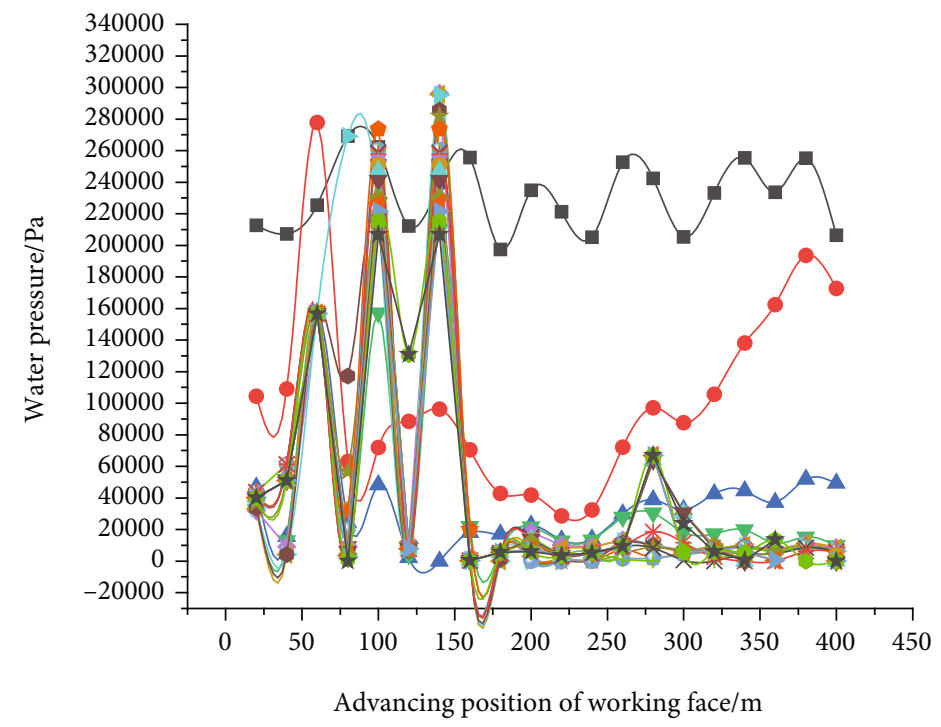

(a) The lower part of model 1 aquifer

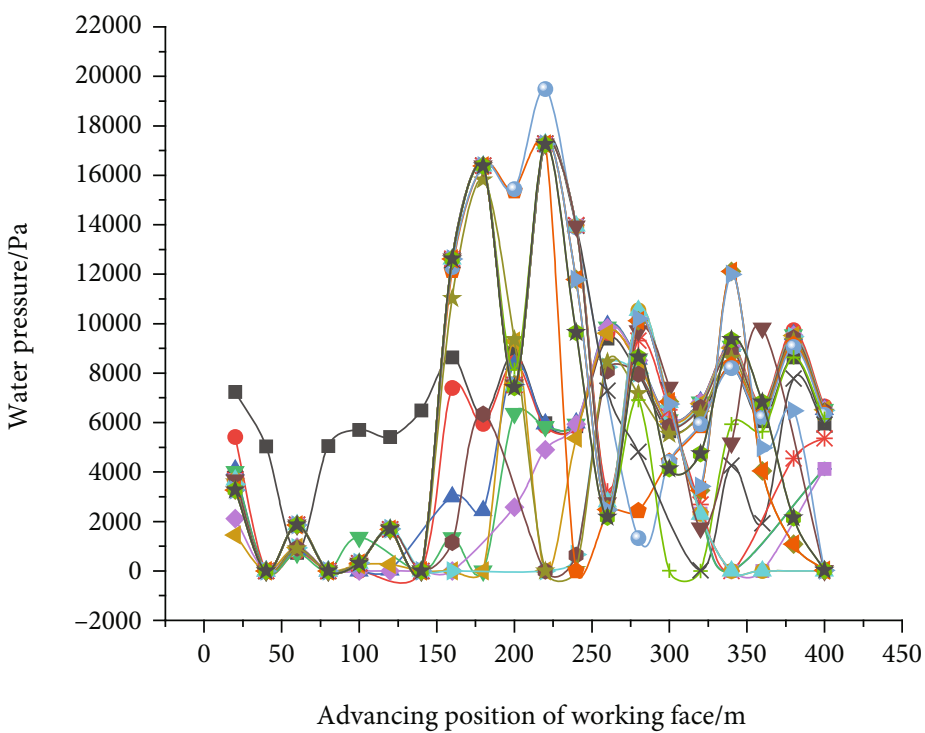

(b) The lower part of model 2 aquifer

Figure 13: Continued. 


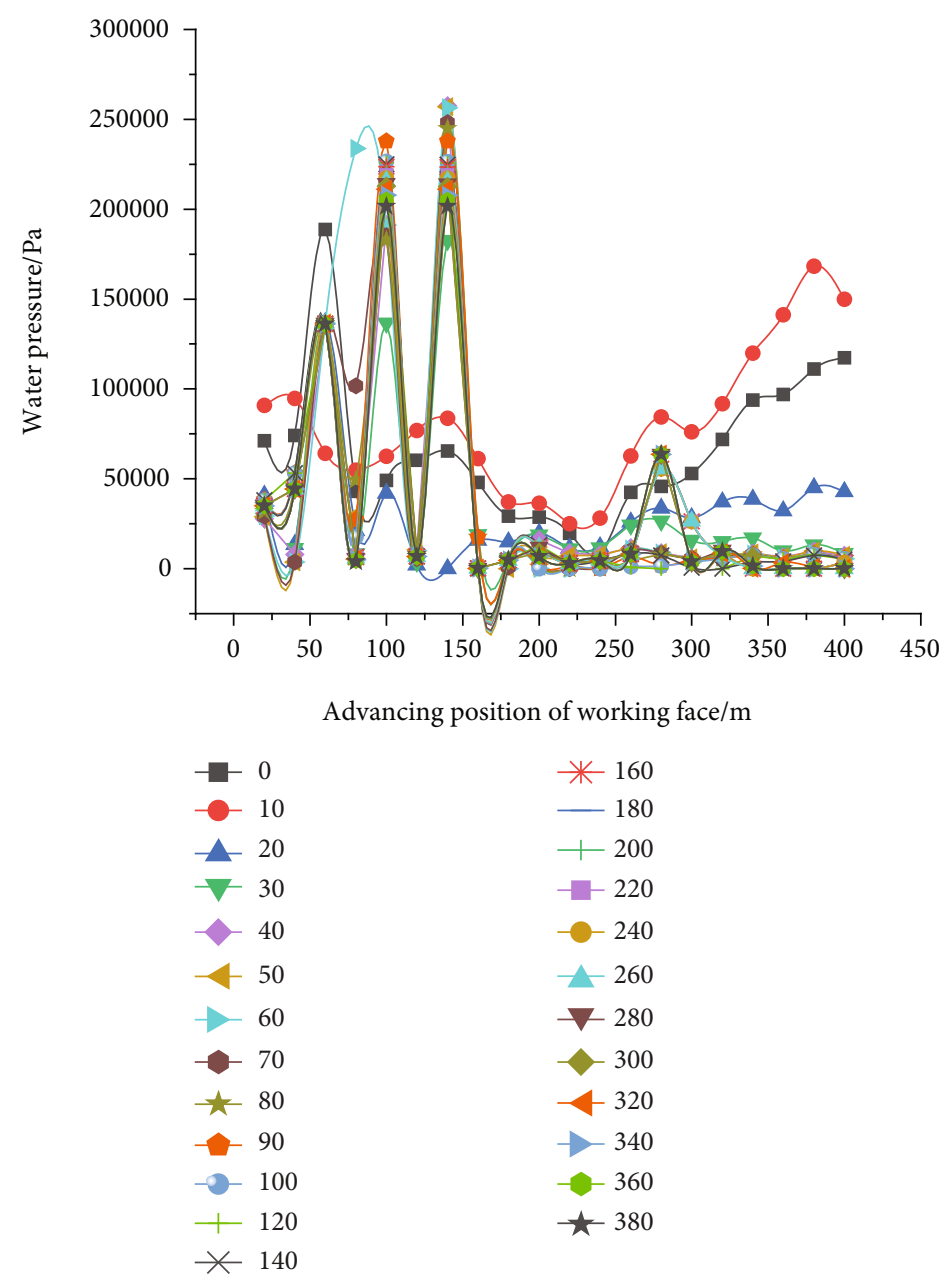

(c) The lower part of model 3 aquifer

Figure 13: Variation law of water pressure in aquiclude.

aquifer is far away from the coal seam, due to the action of the bedrock between the aquifer and the aquiclude, part of the water resources will be stored by the bedrock fissure (cracks) rather than flowing to the goaf, so that the underground reservoir cannot be steadily recharged.

\subsubsection{Analysis of the Water Pressure Change Law at Coal} Roof. In order to characterize the degree of water supply to underground reservoirs by different types of aquifers, the changes in water pressure at coal roof are analyzed. Based on the change law of water pressure in the aquiclude, it can be seen that the change law of water pressure at coal roof varies significantly with the occurrence forms of coal seam and aquifer as well as distance between the two. In model 3 , the change amplitude and increase intensity of water pressure at coal roof are greater compared to the other two models. The change law is similar to that of model 1 (type II aquifer), but the change range of water pressure is bigger compared to model 1 , which means that when the aquifer is a mixed type aquifer; the water source at the coal roof is "recharged" by the two aquifers. The main source for recharging is provided by the lower aquifer, and the water pressure change at coal roof is not a simple superposition of the change values of the water pressure in the two models, which also verifies to a certain extent that part of the water source in the upper aquifer will be stored in the fissure along with the opening and closing of the bedrock fissure.

After the mining of the working face is completed, the water pressure at the open-off cut and the stop line of the working face remains basically stable, and the water pressure in the middle of the working face increases and decreases periodically, indicating that the fissures at both ends of the working face have a greater degree of opening, which becomes a stable water gushing point. However, in the middle part, the fissure is closed due to the recompaction of the rock formation, and the upper part is constantly recharged by water, showing a periodic water pressure change of increase $\rightarrow$ decrease $\rightarrow$ increase.

The change of water pressure at coal roof can directly reflect the damage degree of different types of aquifers under mining as well as the water supply capacity of underground reservoirs in coal mine. From Figure 9, it can be found that the water supply capacity of the underground reservoir is directly related to the "coal-water" occurrence relationship. When it is closer to the coal seam, the recharge capacity is stronger, and the downward flow time of water resources is relatively advanced. When there are multiple aquifers above 


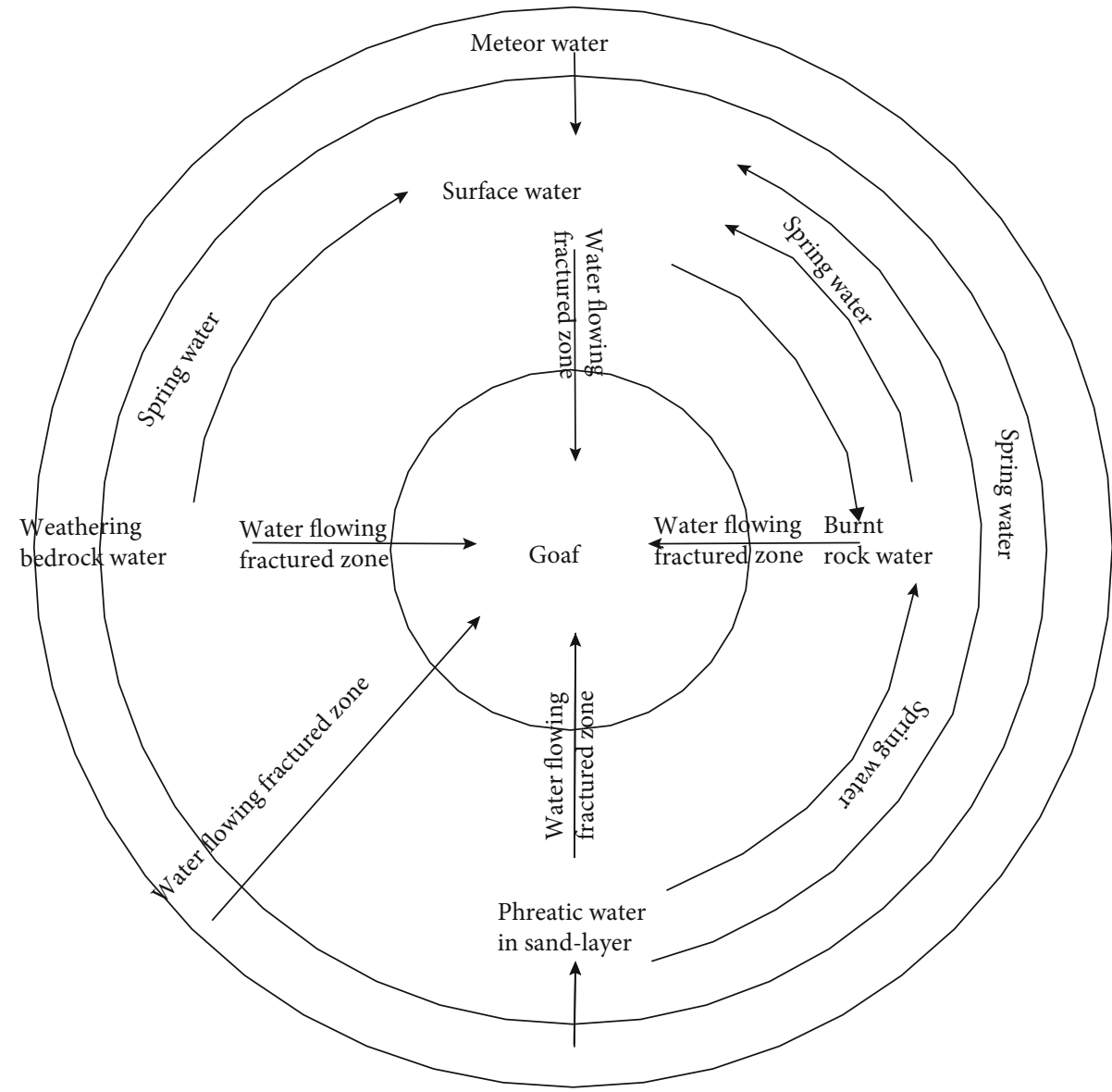

(a) Water supply source in goaf

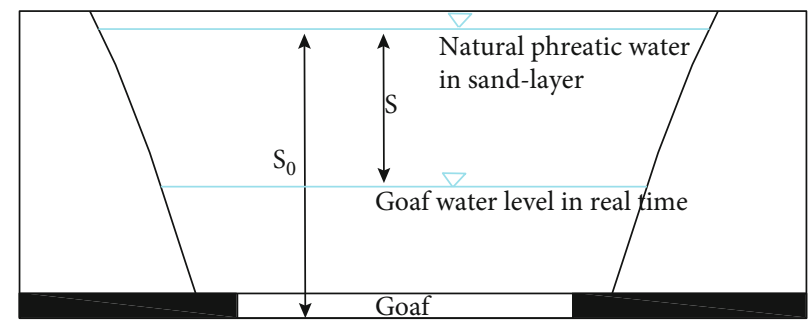

(b) Schematic diagram of water storage in goaf

FIgURe 14: Continued. 


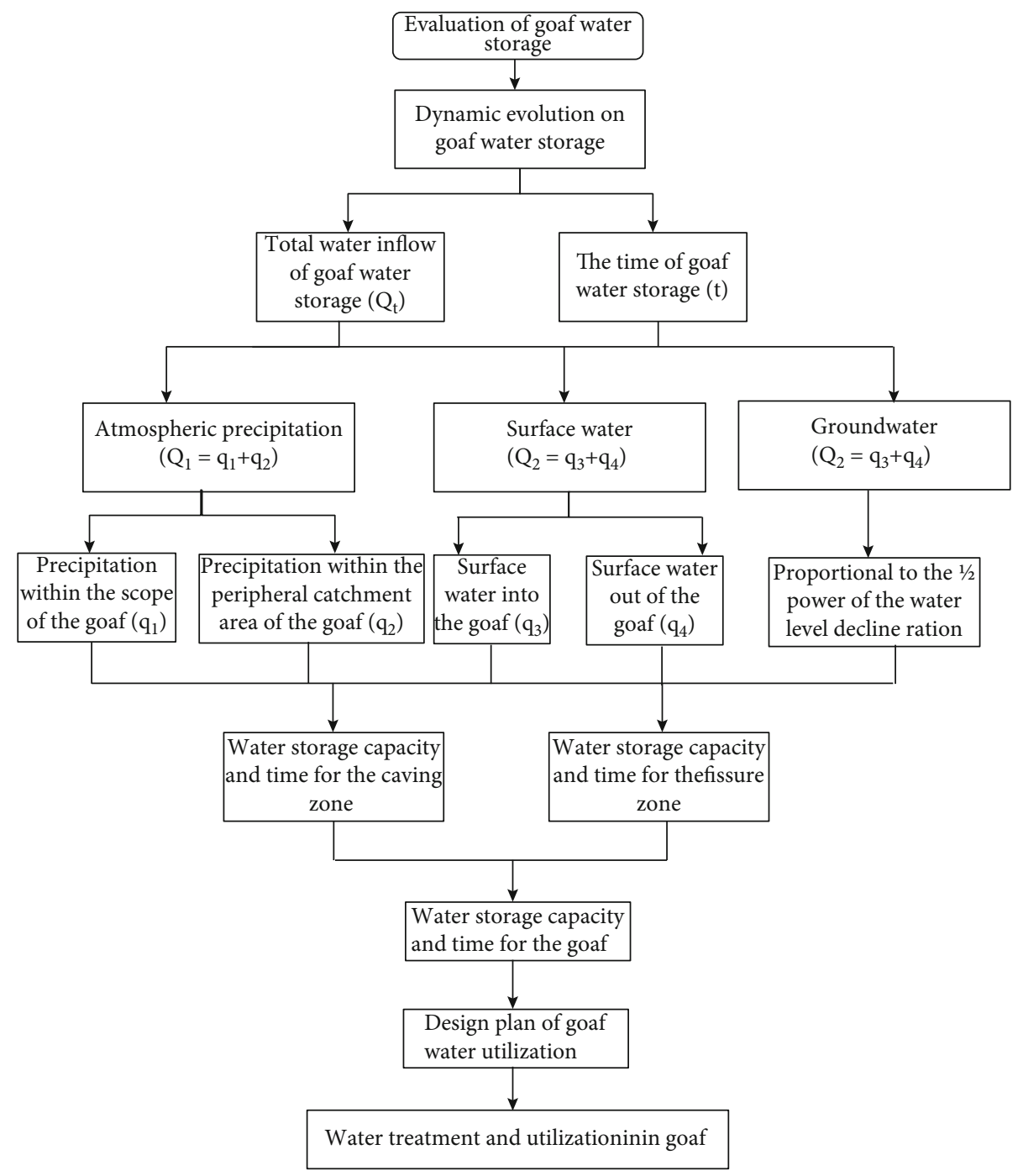

(c) Reserve calculation process

FIGURE 14: Flowchart of evaluation of water storage in goaf.

the coal seam, the aquifer located between the caving zone and the fissure zone is the main "supply aquifer" for the underground reservoir, and the aquifer above it continuously replenishes the lower aquifer under the influence of fissure.

\subsection{Water Source Prediction of Underground Reservoirs} under Different Coal-Water Occurrence Relationships. The water source of underground reservoirs mainly comes from the water resources in the aquifer. After the coal seam is mined, there will be stable water outlets at the open-off cut and stop line. The mining-induced fissures generated in this area have big openings and become one of the stable water sources for underground reservoirs. From the simulation results, the changes in water pressure at coal roof reflect the recharge status of underground reservoirs by aquifers. In order to further analyze the degree of water supply to underground reservoirs provided by different types of aquifers, the water pressure at coal roof is analyzed.

It can be seen from Figure 10 that, in models 2 and 3, there are obvious areas where water pressure increases at both ends of the working face, while in model 1, the water pressure at both ends of the working face does not change significantly, and the water pressure in the lower aquifer shows a hump-shaped distribution. Different types of aquifers show great differences in the cumulative increase trend of coal roof during the advancement of working face. The overall degree of change is ranked as model $3>\operatorname{model} 2>$ model 1, indicating that the coal-water occurrence relationship has a great influence on the water source of underground reservoirs. The farther the aquifer is from the coal seam, the more unstable the recharge to the underground reservoir.

In order to verify the rationality of the numerical simulation, the numerical simulation results were compared with the physical simulation results and on-site monitoring results. The results show that the main "outlet points" derived from physical simulation and numerical simulation are near the open-off cut, and the fissure (water gushing channels) is developed in the tensioned fissure zone above the two ends of the working face [29]. The separation 


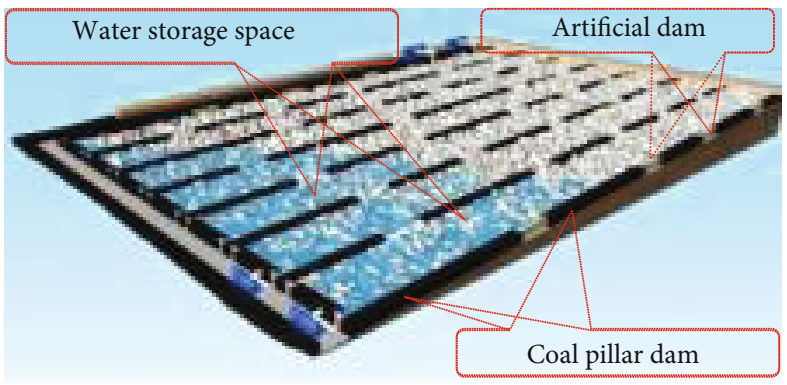

(a) Schematic diagram of underground reservoir in coal mine

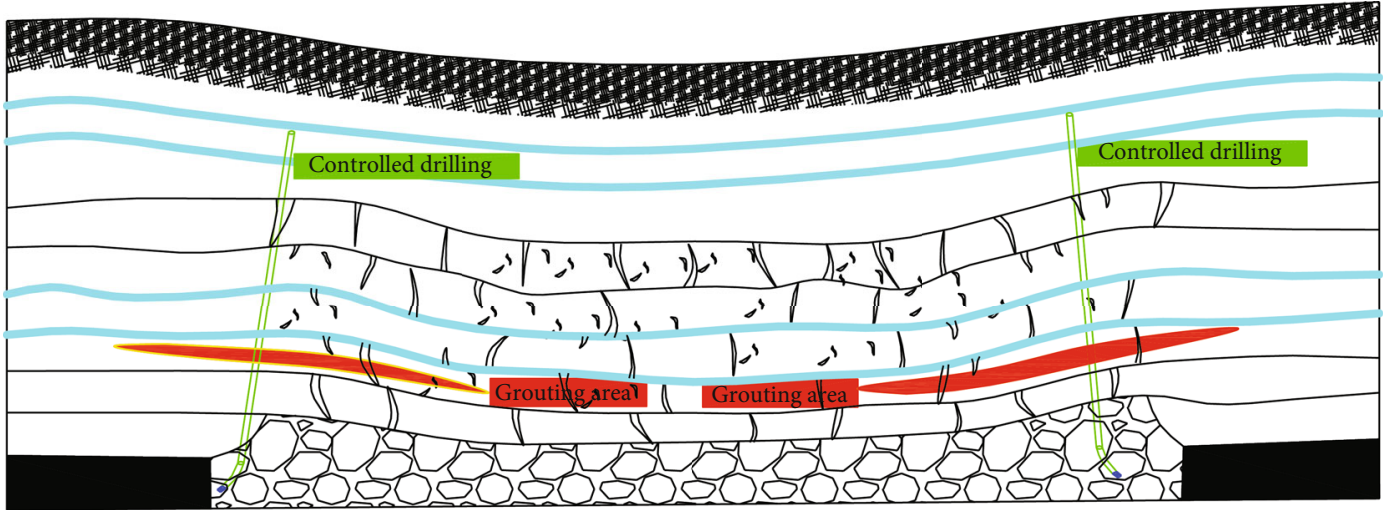

(b) Schematic diagram of adjustment measures

FIGURE 15: Schematic diagram of control method of groundwater reservoir water source based on generalization model.

fissures or horizontal fissures appear just above the working face during the mining process. With the advancement of working face, this part of the fissures is compacted and reclosed, causing the loss of water diversion capability. By comparison with the numerical simulation results, it can be found that great increase of water pressure also appears in the tensile fissure zone at the upper ends of the working face, and there is small water pressure change in the upper compaction zone of the working face. Therefore, the numerical simulation results are basically consistent with the actual results. By analyzing the on-site monitoring results of the aquifer water level (Figure 11(c)), it can be seen that with the advancement of the working face, the water pressure in the aquifer shows a tendency of decrease $\rightarrow$ recover $\rightarrow$ stabilize, which is consistent with the numerical simulation results.

In order to quantitatively analyze the recharging of underground reservoirs by different types of aquifers, according to Darcy's law calculation method, the water inflow $V$ has a relationship with water flow velocity $v$, water flow channel area $S$, and time $t$, as shown in Equation (3).

$$
V=\sum v \cdot d S
$$

where $V$ is the water inflow, $\mathrm{m}^{3} / \mathrm{h} ; v$ is the water flow velocity, $\mathrm{m} / \mathrm{s}$; and $S$ is the cross-sectional area of the water flowing through the rock formation (the coal roof is along the inclination direction of the working face), $\mathrm{m}^{2}$. The monitoring results of the water flow velocity in the monitoring point are shown in Figure 12.
Based on the development degree of the main fissures in the mining process and according to the actual width of the working face, the cross-sectional area of seepage is calculated, and the water inflow results of the three models are finally calculated as well, as shown in Figure 13. The working face width is within the range of $200 \sim 300 \mathrm{~m}$, and the water inflow of each model is obtained. Model 3 has the largest water inflow, which is about $493 \sim 739 \mathrm{~m}^{3} / \mathrm{h}$; model 2 has the smallest water inflow, which is about $252 \sim 377 \mathrm{~m}^{3} / \mathrm{h}$; the water inflow of model 1 is between the two, which is $186 \sim 279 \mathrm{~m}^{3} / \mathrm{h}$. According to the actual occurrence status of the aquifer, the Bulianta Coal Mine can be classified as type III aquifer. According to the analogy method and actual measurement results, the actual water inflow during the mining process of the No. $1^{-2}$ coal seam is $400 \mathrm{~m}^{3} / \mathrm{h}$ by average, which is similar to the simulated value.

\section{Water Source Regulation and Storage Method for Underground Reservoir in Coal Mine considering Coal-Water Occurrence Relationship}

Flowchart of evaluation for water storage in goaf is shown in Figure 14 [1].

$$
\begin{gathered}
Q_{1}=q_{1}+q_{2}, \\
q_{1}=F \cdot \alpha_{1} \cdot h, \\
q_{2}=F_{1} \cdot \alpha_{2} \cdot h,
\end{gathered}
$$


where $F$ is the area of the goaf, $\mathrm{m}^{2} ; \alpha_{1}$ is the precipitation infiltration coefficient of the goaf; $F_{1}$ is the peripheral catchment area of the goaf, $\mathrm{m}^{2} ; \alpha_{2}$ is the precipitation infiltration coefficient in the peripheral catchment area of the goaf; and $h$ is the precipitation intensity of the study area, $\mathrm{m} / \mathrm{d}$.

$$
Q_{2}=q_{3}+q_{4}
$$

where $q_{3}$ is the flow of the surface water into the goaf, $\mathrm{m}^{3} / \mathrm{d}$, and $q_{4}$ is the flow of surface water out of the goaf, $\mathrm{m}^{3} / \mathrm{d}$.

The recharge amount of the underground aquifer for the goaf is related to goaf water storage level. The groundwater inflow is directly proportional to the $1 / 2$ power of decline ratio of the water level, which can be calculated by the following formula:

$$
Q_{3}=Q_{0} \sqrt{\frac{S}{S_{0}}}
$$

where $Q_{0}$ is the water inflow of the goaf before enclosure, $\mathrm{m}^{3} / \mathrm{d} ; S_{0}$ is the drawdown of the phreatic water level before goaf closure, $\mathrm{m}$; and $S$ is the drawdown of the phreatic water level in the goaf water storage, $m$ (Figure 14).

The time $d t$ of goaf water storage presents the drawdown change $d S$ of phreatic water level, so:

$$
\left(Q_{1}+Q_{2}+Q_{0} \sqrt{\frac{S}{S_{0}}}\right) d t=F \mu_{2} d s
$$

where $\mu_{2}$ is the specific yield of the goaf caving zone; assuming $K_{1}=Q_{1}+Q_{2}, K_{2}=Q_{0} / S_{0} \wedge 1 / 2$, following formula can be obtained through integration:

$$
t=\frac{2 F \mu_{2}}{K_{2}^{2}}\left[K_{2}\left(\sqrt{S_{0}}-\sqrt{S}\right)\right]-K_{\ln } \frac{K_{1}+K_{2} \sqrt{S_{0}}}{K_{1}+K_{2} \sqrt{S}}
$$

According to the generalized model of the "coal-water" relationship and the results of numerical analysis, different forms of water source control methods are proposed to ensure that the underground reservoirs have sufficient water supply while the water inflow does not exceed the storage capacity. According to the water supply types of underground reservoirs, they are divided into single-type water sources and mixed-type water sources. The single-type water sources include type I aquifers and type II aquifers, and the mixed aquifers are type III aquifers. The specific regulation and storage method are designed as follows:

\section{(1) Category I (lower aquifer)}

Since the aquifer is located within the fissure zone, the aquifer is greatly damaged by coal mining, and the water source of the aquifer directly enters the goaf. The predicted water inflow volume $V_{1}$ is used as the water source recharge of the underground reservoir, which is compared with reservoir capacity $V$. There are following two situations involved.
In case $1, V>V_{1}$, that is, the aquifer recharge exceeds the designed underground reservoir capacity; the control method is to grout at the bottom of the aquifer above the cut-off line and the stop line to plug the main waterconducting fissures, reduce the mine water inflow, connect the aquifer to the underground reservoir through drilling, arrange water valves in the roadway near the reservoir, adjust the water volume, thereby achieving the purpose of adjusting the water volume of the reservoir (as shown in Figure 15). In case $2, V<V_{1}$, the water inflow of the aquifer is smaller than the designed reservoir capacity. The boreholes arranged in case 1 are used to increase water inflow to the reservoir, and the water source of the underground reservoir is controlled according to the actual water inflow.

\section{(2) Category II (upper aquifer)}

Since this kind of aquifer is far from the coal seam, it is less disturbed and has relatively weak ability to recharge the underground reservoir. When the aquifer water supply meets the reservoir capacity requirements, no large-scale water inrush will occur. When the aquifer water volume does not meet the reservoir capacity requirements, the aquifer can be communicated with the underground reservoir by drilling holes, and devices such as valves can be installed at the pipeline end, in order to guarantee the ecological, production, and domestic water requirement of the mining area in the underground reservoir. Water sources such as aquifers and surface water are introduced into underground reservoirs to ensure the recharge for underground reservoirs. When the water inflow is greater than the designed capacity of underground reservoir, the method of grouting should be taken to block the main water-conducting fissures for type I aquifers.

(3) Category III (contains both upper and lower aquifers)

When the aquifer above the coal seam has both upper and lower aquifers, there is relatively big reservoir water supply. Where type I aquifer is the main source of recharge for the underground reservoir. In order to control the water source of the underground reservoir within a reasonable range, type I aquifer is regarded as the main aquifer, and type II aquifer is subject to auxiliary control according to the amount of water inflow. Grouting and water pipe control are carried out simultaneously for the two types of aquifers to ensure that water inflow matches the storage capacity of underground reservoirs.

\section{Conclusion}

(1) Aiming at the core issue of water supply for underground reservoirs in coal mines, this paper clarifies that the development of water-conducting fissures in aquifers and the formation of water-conducting channels are the key factors leading to the loss of water resources in the aquifer. Based on the occurrence location of aquifer and the development height 
of water-conducting fissure zone, the overlying aquifer of the shallow coal seam is generalized into three types, including the lower aquifer locating between the caving zone and the fissure zone, the upper aquifer locating above the fissure zone, and the mixed aquifer consisting of the above two

(2) Numerical simulation results show that in the process of coal mining, the water pressure of the aquifer presents a variation of decrease $\rightarrow$ increase $\rightarrow$ decrea$\mathrm{se} \rightarrow$ recovery and shows a certain time effect. When the occurrence location of aquifer is farther from coal seam, the time lag is relatively long, the damage degree is smaller, and the recharge of underground reservoir is weaker. The mixed aquifer provides the most abundant water supply to underground reservoir

(3) According to the numerical simulation results, the mine water inflows of different models are calculated. Combining the actual occurrence of Bulianta aquifer (type III aquifer), the rationality of the simulation results is verified. On this basis, the recharging of underground reservoirs by three types of aquifers is analyzed, which shows that mixed aquifers have the strongest recharging capacity, followed by lower aquifers, and upper aquifers with the weakest recharging capacity

(4) In order to ensure that the water supply of underground reservoirs is within a safe and reasonable range, based on the storage capacity of the underground reservoir, a preliminary method is proposed for the water supply control of the underground reservoir, including grouting, blocking of the main water-conducting fissures, and hole drilling (pipes) to divert or inject water into the aquifer

\section{Data Availability}

The raw data required to reproduce these findings cannot be shared at this time as the data also forms part of an ongoing study.

\section{Conflicts of Interest}

The authors declare that they have no conflicts of interest.

\section{Authors' Contributions}

Mingbo Chi and Zhiguo Cao contributed to the conceptualization. Mingbo Chi contributed to the methodology. Yong Zhang contributed to the software. Mingbo Chi and Quansheng $\mathrm{Li}$ contributed to the formal analysis. Baoyang $\mathrm{Wu}$ contributed to the investigation. Bao Zhang contributed to the resources. Yang Yi contributed to the data curation. Xiaoqing Liu and Mingbo Chi contributed to the writing-original draft preparation. Quansheng Li contributed to the writing-review and editing. Mingbo Chi contributed to the funding acquisition. All authors have read and agreed to the published version of the manuscript.

\section{Acknowledgments}

The research is financially supported by the National Natural Science Foundation (52004011) and the National key R \& D plan (2016YFC0501100, 2016YFC0501104).

\section{References}

[1] Q. Wang, W. Li, T. Li, X. Li, and S. Liu, "Goaf water storage and utilization in arid regions of Northwest China: a case study of Shennan coal mine district," Journal of Cleaner Production, vol. 202, pp. 33-44, 2018.

[2] D. Gu, "Theory framework and technological system of coal mine underground reservoir," Journal of China Coal Society, vol. 40, no. 2, pp. 239-246, 2015.

[3] N. Uddin and M. Asce, "Preliminary design of an underground reservoir for pumped storage," Geotechnical \& Geological Engineering, vol. 21, no. 4, pp. 331-355, 2003.

[4] D. Gu and J. Zhang, "Modern coal mining affected to underground water deposit environment in West China mining area," Coal Science and Technology, vol. 40, no. 12, pp. 114117,2012

[5] M. Chi, D. Zhang, L. Honglin et al., "Simulation analysis of water resource damage feature and development degree of mining-induced fracture at ecologically fragile mining area," Environmental Earth Sciences, vol. 78, no. 3, p. 88, 2019.

[6] Z. Li, J. Xu, S. Yu, J. Ju, and J. Xu, "Mechanism and prevention of a chock support failure in the longwall top-coal caving faces: a case study in Datong coalfield, China," Energies, vol. 11, no. 2, p. 288, 2018.

[7] L. Zhao, C. Sun, P. Yan et al., "Dynamic changes of nitrogen and dissolved organic matter during the transport of mine water in a coal mine underground reservoir: column experiments," Journal of Contaminant Hydrology, vol. 223, article 103473, 2019.

[8] R. Stone and D. F. Snoeberger, "Cleat orientation and areal hydraulic anisotropy of a Wyoming coal aquifer," Groundwater, vol. 15, no. 6, pp. 434-438, 1977.

[9] X. H. Xie, B. Y. Su, Y. F. Gao, and X. B. Duan, "Numerical study on water inrush above a confined aquifer in coal mining using hydro-fracturing," Chinese Journal of Rock Mechanics and Engineering, vol. 24, no. 6, pp. 987-993, 2005.

[10] D. Zhang, G. Fan, Y. Liu, and L. Ma, "Field trials of aquifer protection in longwall mining of shallow coal seams in China," International Journal of Rock Mechanics and Mining Sciences, vol. 47, no. 6, pp. 908-914, 2010.

[11] Q. Zhang, S. Luo, L. Zhao et al., "Effect of Darcy flux on the release of dissolved organic matter and nitrogen from coal gangue in a coal mine underground reservoir: column experiments," Chemical Geology, vol. 545, article 119652, 2020.

[12] X. Kong, Z. Xu, R. Shan, S. Liu, and S. C. Xiao, "Investigation on groove depth of artificial dam of underground reservoir in coal mines," Environmental Earth Sciences, vol. 80, no. 6, pp. 1-17, 2021.

[13] Q. Yao, C. Tang, Z. Xia et al., "Mechanisms of failure in coal samples from underground water reservoir," Engineering Geology, vol. 267, article 105494, 2020. 
[14] M. D. Kozar, M. C. KJ, J. Q. Britton, and B. M. Blake Jr., Hydrogeology, Groundwater Flow, and Groundwater Quality of an Abandoned Underground Coal-Mine Aquifer, Elkhorn Area, West Virginia, West Virginia Geological and Economic Survey, 2017.

[15] T. Roje-Bonacci and O. Bonacci, "The possible negative consequences of underground dam and reservoir construction and operation in coastal karst areas: an example of the hydroelectric power plant (HEPP) Ombla near Dubrovnik (Croatia)," Natural Hazards and Earth System Sciences, vol. 13, no. 8, pp. 2041-2052, 2013.

[16] B. F. Wang, B. Liang, J. G. Wang, K. M. Sun, and H. B. Chi, "Experiment study on rock bulking of coal mine underground reservoir," Rock and Soil Mechanics, vol. 39, no. 11, pp. 40864092, 2018.

[17] A. Royer-Lavallée, C. M. Neculita, and L. Coudert, "Removal and potential recovery of rare earth elements from mine water," Journal of Industrial and Engineering Chemistry, vol. 89, pp. 47-57, 2020.

[18] H. H. Hannan and L. Broz, "The influence of a deep-storage and an underground reservoir on the physicochemical limnology of a permanent Central Texas river," Hydrobiologia, vol. 51, no. 1, pp. 43-63, 1976.

[19] F. Wang, N. Liang, and G. Li, "Damage and failure evolution mechanism for coal pillar dams affected by water immersion in underground reservoirs," Geofluids, vol. 2019, 12 pages, 2019.

[20] S. J. Schatzel, C. O. Karacan, H. Dougherty, and G. V. R. Goodman, "An analysis of reservoir conditions and responses in longwall panel overburden during mining and its effect on gob gas well performance," Engineering Geology, vol. 127, no. 3, pp. 65-74, 2012.

[21] Federation W E, APH Association, Standard Methods for the Examination of Water and Wastewater, American Public Health Association (APHA), Washington, DC, USA, 2005.

[22] I. A. Wright, B. McCarthy, N. Belmer, and P. Price, "Subsidence from an underground coal mine and mine wastewater discharge causing water pollution and degradation of aquatic ecosystems," Water, Air, \& Soil Pollution, vol. 226, no. 10, p. 348, 2015.

[23] L. Ma and R. F. Spalding, "Effects of artificial recharge on ground water quality and aquifer storage recovery," Journal of the American Water Resources Association, vol. 33, no. 3, pp. 561-572, 1997.

[24] R. Zhang, Z. Jiang, H. Zhou, C. Yang, and S. Xiao, "Groundwater outbursts from faults above a confined aquifer in the coal mining," Natural Hazards, vol. 71, no. 3, pp. 1861-1872, 2014.

[25] H. Song, J. Xu, J. Fang, Z. Cao, L. Yang, and T. Li, "Potential for mine water disposal in coal seam goaf: investigation of storage coefficients in the Shendong mining area," Journal of Cleaner Production, vol. 244, article 118646, 2020.

[26] A. H. Wilson, "The stability of underground workings in the soft rocks of the coal measures," International Journal of Mining Engineering, vol. 1, no. 2, pp. 91-187, 1983.

[27] A. Mortazavi, F. P. Hassani, and M. Shabani, "A numerical investigation of rock pillar failure mechanism in underground openings," Computational Geosciences, vol. 36, no. 5, pp. 691697, 2009.

[28] H. Wang, D. Zhang, X. Wang, and W. Zhang, "Visual exploration of the spatiotemporal evolution law of overburden failure and mining-induced fractures: a case study of the Wangjialing Coal Mine in China," Minerals, vol. 7, no. 3, p. 35, 2017.
[29] P. Huang and J. Chen, "Recharge sources and hydrogeochemical evolution of groundwater in the coal-mining district of Jiaozuo, China," Hydrogeology Journal, vol. 20, no. 4, pp. 739-754, 2012. 